\title{
Beneficial Effects of Celastrol on Immune Balance by Modulating Gut Microbiota in Dextran Sodium Sulfate-Induced Ulcerative
}

\section{Colitis}

Mingyue $\mathrm{Li}^{\mathrm{a}} *$, Weina Guo ${ }^{\mathrm{a} *}$, Yalan Dong ${ }^{\mathrm{a} *}$, Wenzhu Wang ${ }^{\mathrm{a} *}$, Chunxia Tian ${ }^{\mathrm{a}}$, Zili Zhang ${ }^{\mathrm{a}}$, Ting Yu ${ }^{\mathrm{a}}$, Haifeng Zhou ${ }^{\mathrm{a}}$, Yang Gui ${ }^{\mathrm{a}}$, Kaming Xue ${ }^{\mathrm{a}}$, Junyi Li ${ }^{\mathrm{a}}$, Feng Jiang ${ }^{\mathrm{b}}$, Alexey Sarapultsev ${ }^{\mathrm{c}}$, Shanshan Luo ${ }^{\mathrm{d}}$, Heng Fan ${ }^{\mathrm{a}}$, Desheng $\mathrm{Hu}^{\mathrm{a}}$

${ }^{\text {a }}$ Department of Integrated Traditional Chinese and Western Medicine, Union Hospital, Tongji Medical College, Huazhong University of Science and Technology, Wuhan 430022, China

${ }^{\mathrm{b}}$ Tianjin University of Traditional Chinese Medicine, Tianjin 301617, China

${ }^{\mathrm{c}}$ Institute of Immunology and Physiology, Ural Branch of the Russian Academy of Science, Ekaterinburg 620049, Russia

${ }^{\mathrm{d}}$ Institute of Hematology, Union Hospital, Tongji Medical College, Huazhong University of Science and Technology, Wuhan 430022, China

*These authors contributed equally.

\section{Corresponding Author:}

Desheng $\mathrm{Hu}, \mathrm{PhD}$

Department of Integrated Traditional Chinese and Western Medicine, Union Hospital, Tongji Medical College, Huazhong University of Science and Technology, Wuhan 430022, China.

Tel: $+86-27-8572-6395$.

Email: desheng.hu@ hust.edu.cn

Running Title: CSR ameliorates ulcerative colitis in a gut microbiota-dependent manner 


\section{Abstract}

Ulcerative colitis (UC) is a chronic inflammatory bowel disease caused by multi-factors including colonic inflammation and microbiota dysbiosis. Previous studies have indicated that Celastrol (CSR) has strong anti-inflammatory and immune-inhibitory effects. Here, we investigated the effects of CSR on colonic inflammation and the mucosal immunity in an experimental colitis model, and addressed the mechanism by which CSR preforms the protective effect. We characterized the therapeutic effects and the potential mechanism of CSR in treating UC using histological staining, intestinal permeability assay, cytokine assay, flow cytometry, fecal microbiota transplantation (FMT), 16S rRNA sequencing, untargeted metabolomics, and cell differentiation approaches. CSR administration significantly ameliorated DSS-induced colitis, as evidenced by the recovery of body weight and colon length, decreased disease activity index (DAI) score, as well as decreased intestinal permeability. CSR down-regulated the secretion of proinflammatory cytokines, upregulated the anti-inflammatory mediators, and improved the balances of Treg/Th1 and Treg/Th17 to maintain colonic immune homeostasis. However, the protective effects of CSR disappeared when the antibiotic cocktail was applied to deplete the gut microbiota, and the gut microbiota-mediated effect was confirmed by FMT. Furthermore, CSR treatment increased the gut microbiota diversity and composition, and raised the metabolic productions of pyruvate and adenosine, which probably involve in gut microbiota mediated protective effect. In conclusion, CSR ameliorates colonic inflammation in a gut microbiota-dependent manner. The underlying protective mechanism is associated with the rectified Treg/Th1 and Treg/Th17 balance, and increased pyruvate and adenosine production. The study provided the solid evidence that CSR might be a promising therapeutic drug for UC.

Key words: ulcerative colitis; Celastrol; gut microbiota; Treg/Th1 balance; Treg/Th17 balance; metabolomics

Abberviations: UC: ulcerative colitis; CSR: celastrol; FMT: fecal microbiota transplantation; Th cells: T helper cells; Treg: regulatory T; DSS: dextran sodium 
sulfate; LPL : lamina propria lymphocytes.

\section{Introduction}

Ulcerative colitis (UC) is one of two major forms of inflammatory bowel disease and involves diffuse inflammation of the colonic mucosa. With the poor quality of life, high morbidity and risk of colitis-related colorectal cancer, UC has become a public health threat $[1,2]$. The current treatment strategy for UC is based on the severity, distribution, and pattern of disease, including the use of oral and/or topical 5-aminosalicylic acid as the first-line medication for induction and maintenance therapy, nonsystemic and systemic corticosteroids, or a combination of anti-tumor necrosis factor and immunomodulator therapy[3,4]. Due to the low remission rate of new drugs or the secondary loss of response, the patients unresponsive to these therapies suffer from high morbidity associated with delayed surgery[5].

The pathogenesis of UC still remains unclear. Several factors, including the genetic susceptibility, dysregulated immune responses, imbalance of gut microbiota, and environmental exposure have been reported to be implicated[6]. The imbalance between $\mathrm{T}$ helper (Th) cells and regulatory $\mathrm{T}$ (Treg) cells has been proved to be correlated with the occurrence and severity of UC[7]. During UC progression, Th1 and Th17 cells are usually increased and exert pathogenic effects by releasing the proinflammatory cytokines including IFN- $\gamma$ and IL-17A, respectively, while Treg cells, which inhibit Th1 and Th17 activities through intercellular communication, are decreased[8-13].

Dysbiosis of gut microbiota could skew the balance of Treg/Th17 cells, and then trigger exaggerated inflammatory responses in UC[14]. It has been reported that the composition of the gut microbiota in patients with UC markedly differs from those of healthy individuals[15]. Furthermore, the dysbiosis between probiotics and pathogenic bacteria, and the reduction of bacterial diversity play an important role in the development of UC[16, 17]. In addition, the gut microbiota-derived metabolites function as an intermediate link between microbiota and local immune responses. For 
instance, it has been confirmed that accumulated short-chain fatty acid can alleviate colitis by regulating Treg/Th17 balance[18-20]. Therefore, maintaining the homeostasis of gut microbiota might be a promising therapeutic strategy for UC.

Celastrol (CSR), isolated from the root xylem of tripterygium wilfordii (TW), a Chinese herb used in Traditional Chinese Medicine for several centuries. With strong antioxidant, anti-inflammatory, and anticancer properties, an increasing number of studies were published highlighting the medicinal usefulness of celastrol in diverse clinical areas, namely, rheumatoid arthritis, systemic lupus erythematosus, inflammatory bowel diseases, osteoarthritis and allergy, as well as in cancer, neurodegenerative disorders[21]. In mice models of DSS-induced colitis, it has been found that celastrol ameliorates acute intestinal injury and prevents the loss of intestinal epithelial homeostasis through the reduction of colonic oxidative stress, inhibition of NLRP3-inflammasome and IL-23/IL-17 pathway, reduction of inflammatory cytokines and increase in IL-10 and TNF levels, attenuation of neutrophil infiltration and upregulation of E-cadherin expression[22, 23].

However, the intrinsic therapeutic mechanism of CSR on UC still needs to be clarified. Given the vital role of gut microbiota dysbiosis and immune dysregulation in the pathogenesis of UC, we sought to address the potential impacts of CSR on gut microecosystem and immune system in dextran sodium sulfate (DSS)-induced colitis mouse model.

\section{Results}

\section{Celastrol administration ameliorated DSS-induced colitis}

To investigate the therapeutic effect of CSR (Figure S1A) on UC, DSS-induced colitis model was established in this study. Mice were treated with 3.0\% DSS in the drinking water, and CSR suspended in saline was administered by oral gavage for 7 days (Figure 1A). Compared with the DSS group, CSR administration significantly ameliorated DSS-induced colitis, as evidenced by the markedly reduced body weight loss (Figure 1B), and improved colon length (Figure 1C). Furthermore, DAI score 
based on the assessment of stool consistency, bloody stool, and weight loss concorded with the above results, validating the curative effect of CSR (Figure 1D). To test the intestinal permeability, the mice were gavaged with FITC-dextran 4 hours before being euthanized. Compared to control group, mice with TG treatment exhibited decreased serum level of FITC-dextran, indicating the relatively intact epithelial barrier (Figure 1E). Additionally, H\&E staining were performed to evaluate the extent of injuries of colon. Compared with DSS-treated mice, the distorted crypts, loss of goblet cells, epithelial injury, and the infiltration of inflammatory cells in the mucosa and submucosa were dramatically alleviated in mice of the DSS+CSR+group. These observations indicated that CSR well controlled colon inflammation and maintained epithelial barrier integrity (Figure 1F), which was further confirmed by Alcian blue staining showing the intensity of goblet cells (Figure S1B). Since tight junction plays a vital role in maintaining the barrier of epithelium in colon, next we assessed the expression of tight junction related proteins. Data revealed that DSS inhibited the expression of Occludin, Cdh1, Zo-1 and Muc2, which were rescued by CSR treatment (Figure 1G).

Immune cells and secreted inflammatory cytokines are important mediators for immune homeostasis in the gut. Hence, we examined these mediators in the colon tissues. The proinflammatory cytokines, including Il-1 $\beta, I l-17 a$, Ifn- $\gamma, I l-6$, and Tnf- $\alpha$ were down-regulated, while the anti-inflammatory mediators $T g f-\beta$ and $I l-10$ were up-regulated in colon tissues of mice in the DSS+CSR+ group (Figure 1H and 1I). The frequencies of IFN $-\gamma^{+} \mathrm{CD} 4^{+}$and $\mathrm{IL}-17 \mathrm{~A}^{+} \mathrm{CD} 4^{+} \mathrm{T}$ cells in spleen and MLN in DSS+CSR+ group were reduced (Figure S1C). Meanwhile, in spleen, MLN and

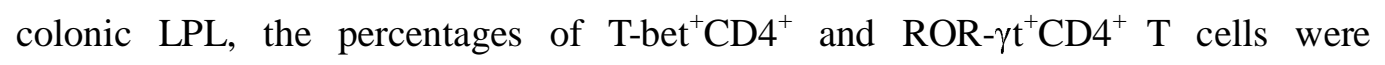
down-regulated, and Foxp $3^{+} \mathrm{CD}^{+} \mathrm{T}$ cells were up-regulated in DSS+CSR+ group mice (Figure 1J and 1K). Together, these results indicated that CSR can prevent DSS-induced colitis.

\section{Celastrol up-regulated the differentiation of Treg cells in vitro}

To further explore whether CSR directly regulate $\mathrm{T}$ cell differentiation, naive $\mathrm{CD} 4^{+} \mathrm{T}$ 
cells were isolated from spleen of WT mice, and were co-cultured with different concentration of CSR under the corresponding conditions for Th1, Th17 and Treg cells differentiation in vitro. The results showed that CSR had no effect on the differentiation of IFN- $\gamma^{+} \mathrm{CD} 4^{+} \mathrm{T}$ cells and IL-17A ${ }^{+} \mathrm{CD} 4^{+} \mathrm{T}$ cells in the indicated CSR concentration. However, Foxp $3^{+} \mathrm{CD} 4^{+}$cells were elevated when the concentration of CSR is $4 \mu \mathrm{mol} / \mathrm{L}$ (Figure S2).

\section{Celastrol alleviated colitis in a gut microbiota-dependent manner}

To investigate whether gut microbiota mediated the protective effect of CSR on DSS-induced colitis, the WT mice were treated with quadruple antibiotic cocktail (ABX) for gut microbiota depletion before DSS treatment (Figure 2A). Following the 3-week ABX treatment, the gut microbiota Eubacteria, Lactobacilius, MIB and Eubacterium rectale-Clostridium coccoides were significantly decreased in fecal samples of ABX-treated mice (Figure S3A), which were consistent with previous research. Moreover, there was no difference in the morphological of liver, kidney, intestine, or colon, and the serum levels of ALT, AST, BUN, and CRE after ABX treatment compared to untreated mice, indicating the non-organ toxicity of $\mathrm{ABX}$ (Figure S3B and S3C). Impressively, the theraputic effect of CSR was reversed after gut microbiota depletion. $\mathrm{ABX}+\mathrm{DSS}+$ group mice and $\mathrm{ABX}+\mathrm{DSS}+\mathrm{CSR}+$ group mice displayed no significant difference in the following index, such as body weight loss (Figure 2B), colon length (Figure 2C), DAI score (Figure 2D), intestinal permeability (Figure 2E), histological changes and scores (Figure 2F), goblet cells(Figure S4A), tight junction proteins (Figure 2G), proinflammatory cytokines and anti-inflammatory mediators (Figure 2H and 2I). In addition, the percentages of T-bet ${ }^{+} \mathrm{CD} 4^{+}, \mathrm{ROR}-\gamma \mathrm{t}^{+} \mathrm{CD} 4^{+}$and Foxp $3^{+} \mathrm{CD} 4^{+} \mathrm{T}$ cells in spleen, MLN and colonic LPL (Figure 2J and 2K), and IFN $-\gamma^{+} \mathrm{CD} 4^{+}$and $\mathrm{IL}-17 \mathrm{~A}^{+} \mathrm{CD} 4^{+} \mathrm{T}$ cells in spleen and MLN (Figure S4B) showed no significant difference between $\mathrm{ABX}+\mathrm{DSS}+$ group and $\mathrm{ABX}+\mathrm{DSS}+\mathrm{CSR}+$ group. These results demonstrated that the protective effect of CSR on colitis was gut microbiota-dependent.

\section{Fecal microbial transplantation mitigated colitis}


To gain deeper insight into the protective effect of CSR about how it regulated the gut microbiota, we conducted FMT experiment. Fecal microbiota from mice of the DSS-CSR-, DSS+CSR- and DSS+CSR+ group were transferred into DSS-induced colitis mice (Figure 3A). Compared to mice with FMT from DSS-CSR- treated mice, mice received FMT from DSS+CSR- treated mice showed more serious weight loss (Figure 3B) and colon shortening (Figure 3C), higher DAI score (Figure 3D), poorer intestinal permeability (Figure 3E), higher histology score (Figure 3F), lower levels of goblet cells (Figure S5A) and tight junction proteins (Figure 3G), which were completely reversed in mice with FMT from DSS+CSR+ treated mice. Representative microscopic H\&E staining and Alcian blue staining pictures are shown in Figure 3F and Figure S5A. Furthermore, compared to mice with FMT from DSS-CSR- treated mice, the expression of related proinflammatory cytokines, Th1, Th17 cells and their transcription factors were increased, and the anti-inflammatory counterparts were decreased in mice received fecal microbiota from DSS+CSR- mice. Again, all aforementioned disease-modifying tendencies were abrogated in mice received fecal microbiota from DSS+CSR+ mice (Figure 3H and 3K, Figure S5B). These FMT results indicated that gut microbiota in CSR treated mice was responsible for alleviated colitis.

\section{Celastrol significantly influenced the gut microbiota}

The gut microbiota has been shown to play important roles in maintaining intestinal homeostasis and T cell functions. High-throughput gene-sequencing analysis of $16 \mathrm{~S}$ rRNA in fecal bacterial DNA isolated from control group, DSS+ group and DSS+CSR+ group mice were performed to investigate whether CSR altered microbiome. We initially measured gut microbial alpha diversity through different indices, including observed species, Chao, ace and PD_whole tree, and found that CSR-treated mice harbored a microbiota with higher alpha diversity relative to that of the DSS+ group (Figure 4A). To further explore the diversity of the microbiome, we performed beta-diversity to generate principal coordinate analysis (PCoA) using binary jaccard distance and unweighted-unifrac distance algorithms. The obvious 
clustering separation between OTUs reveals the different community structures of the three groups, indicating that these communities are different in composition and structure (Figure 4B).

Subsequently, we evaluated the gut microbiota in all samples to find possible compositional differences among the three groups. At the phylum level, in all samples the most abundant phyla were Bacteroidetes and Firmicutes. Additionally, the ratio of Firmicutes to Bacteroidetes $(\mathrm{F} / \mathrm{B})$ showed no significant difference among the three groups (Figure S6A). Taxonomic compositions of the three groups were also compared at the class/order/family level (Figure S6B and S6D). At the genus level, the three groups displayed obviously differential biological compositions (Figure S6E). The different bacterial genera with higher relative abundance in three groups were analyzed. Alloprevotella and Odoribacter displayed relatively higher abundance in DSS+ and DSS+CSR+ groups, whereas the unidentified_Lachnospiraceae were more abundant in control group (Figure S6F).

To confirm which bacteria was changed by CSR treatment, we conducted high-dimensional class comparisons using the linear discriminant analysis (LDA) of effect size (LEfSe), and looked for differences in the predominance of bacterial communities among the three groups (Figure 4C and 4D). According to the analysis results, Odoribacter and Marinifilaceae were the key types of bacteria resulting in the gut microbiota dysbiosis in DSS-treated group. However, Prevotellaceae, Alloprevotella, Paraprevotella and Butyricicoccus displayed a relative enrichment in the DSS+CSR+ group, which might be associated with the CSR-mediated alleviation of colitis. Based on the OUT abundance at genus levels, the inter-group difference in the comparison heatmap was shown for analyzing gut microbiota among the three groups (Figure 4E). Similarly, the genus Alloprevotella and Butyricicoccus displayed a relatively higher abundance in the DSS+CSR+ group, while the genus Odoribacter was significantly enriched in the DSS+ group, which was consistent with the LEfSe analysis results. In conclusion, CSR treatment significantly altered the gut microbiota diversity and composition. 


\section{Celastrol significantly alters gut metabolomics}

Metabolites were the major executors of gut microbiota in the pathogenesis of inflammatory diseases. Hence, to address the role of CSR in affecting gut metabolites, we performed non-target metabolomics analysis on the isolated feces of mice from DSS+ group and DSS+CSR+ group. Partial least-squares discrimination analysis (PLS-DA) and Hierarchical clustering revealed that the metabolomic profile of DSS+CSR+ mice was significantly different from that of DSS+ mice (Figure 5A and 5B). Under negative and positive ion mode, 24 metabolites were more abundant in DSS+CSR+ mice than in DSS+ mice (Figure 5C and 5D). Then the influences of these metabolites on the differentiation of naïve CD4+ T cells were explored in vitro , and pyruvate and adenosine showed their potential functions. In details, pyruvate down-regulated the differentiation of IFN- $\gamma^{+} \mathrm{CD} 4^{+} \mathrm{T}$ cells and $\mathrm{IL}-17 \mathrm{~A}^{+} \mathrm{CD} 4^{+} \mathrm{T}$ cells (Figure 6A and 6B), and adenosine up-regulated the differentiation of Foxp $3^{+} \mathrm{CD} 4^{+} \mathrm{T}$ cells in vitro (Figure 6C). In summary, CSR administration obviously altered the metabolomics in colon, which in turn affected the differentiation of naïve T cells.

\section{Discussion}

UC is a subtype of inflammatory bowel disease (IBD) characterized by chronic recurrent inflammation of the colonic mucosa. The clinical manifestations are recurrent abdominal pain, loose and bloody stools. Currently, drugs applied in the treatment are challenged by insufficient effect, drug dependence, adverse reactions and high costs. Thus, it is worthy of in-depth investigation to find new UC therapies with better performance. CSR, with prominent anti-inflammatory and antioxidant effects, is anticipated to be an effective element in TW, which has been "clinically" tested in the Traditional Chinese Medicine for thousand years. In this study, we systematically studied the therapeutic effects of CSR on DSS-induced colitis in mice and its potential mechanism (Figure 7).

The symptom of DSS-induced colitis in mice is similar to that of human UC, and the DSS-induced colitis model is well-acknowledged and wide-used animal model for studying UC currently[24]. DSS-induced colitis in mice reveals the typical UC 
features, including inflammation that starts from the distal colon and then involves the proximal colon, body weight loss, shortening of colon length, mucosal ulcers, and infiltration of inflammatory granulocytes[25]. According to the results, CSR significantly affected the intensity of intestinal inflammation, reversing the imbalance of Treg/Th17 and Treg/Th1 in the intestinal mucosa. These results are similar to those reported in previous studies, where the beneficial effects of CSR on the Th17/Treg cell-mediated responses were revealed in animal models of autoimmune arthritis and autoimmune encephalomyelitis[26, 27].

Gut microbiota dysbiosis plays a vital role in the pathogenesis of UC[28, 29], and various therapeutic microbial manipulations (such as antibiotics, probiotics, prebiotics, and microbiota transplantation) have been proved to be a promising treatment strategy[30-32]. To reveal the underlying therapeutic mechanism of CSR action, we investigated whether gut microbiota contributes to its protective effect. It is worth noting that there was no significant difference in the severity of colon inflammation between the $\mathrm{ABX}+\mathrm{DSS}+$ group and the $\mathrm{ABX}+\mathrm{DSS}+\mathrm{CSR}+$ group, which means that the protective role of CSR disappeared after depleting gut microbiota. Subsequently, we conducted FMT to confirm that the effect was afforded by microbiota and was transferable. In contrast to the feces from DSS+CSR- mice, feces from DSS+CSR+ mice alleviated the inflammatory response and rectified the imbalance of Treg/Th1 and Treg/Th17 in DSS-induced mice. The experiments in vitro have confirmed that, without the participation of microbiota, CSR indeed lost its regulatory role in the differentiation of Th1, Th17 cells, and Treg cells. Therefore, the immune-mediating action of CSR was due to its influence on the microbiota.

According to the literature, UC patients show a decrease in the biological diversity of gut microbiota composition, which is called dysbiosis and characterized by the loss of beneficial bacteria and the expansion of pathogenic bacteria[14]. For instance, in UC patients, the relative abundance of beneficial bacterial species, such as Prevotella copri and the butyrate-producing bacterium Faecalibacterium prauznitzii, have been shown to decrease remarkably. In order to further clarify the influence of CSR on the 
structure and composition profiles of gut microbiota, the 16S rRNA sequencing was conducted. In this study, the alpha diversity indices, including observed species, Chao, ace and PD_ whole tree indexes, revealed that CSR-treated mice were characterized by a higher diversity relative to that of the DSS-treated group. The beta diversity analysis has revealed the DSS+CSR+ group mice harbored an apparent clustering separation from DSS+ group mice through PCoA, indicating that CSR treatment markedly transformed the biological community structures. Consequently, the conducted LEfSe analysis between the control, DSS+, and DSS+CSR+ groups revealed that Odoribacter and Marinifilaceae were the key types of bacteria in DSS-treated group. Meanwhile, four signature bacterial taxa, including Prevotellaceae, Alloprevotella, Paraprevotella and Butyricicoccus displayed a relative enrichment in the DSS+CSR+ group. Given the dysbiosis in IBD patients is associated with a decrease in the number of SCFAs/butyrate-producing bacteria[33], the obtained results may indicate a favorable action of CSR on the course of UC. Moreover, the genus Prevotellaceae, with the most predominance and the highest LDA score in the DSS+CSR+ group, was reported to be associated with the remission of IBD[34]. Additionally, Alloprevotella was reported to be related to the decreased lifetime of cardiovascular disease[35], which strengthen the importance of the present findings.

Previous study illuminated that the metabolites of gut microbiota, such as SCFAs, impose profound impact on inflammation of $\operatorname{IBD}[36]$. We used untargeted metabolomics analysis to investigate the potential alteration in metabolome after CSR treatment. The results showed that the concentration of pyruvate, L-ascorbate and adenosine were higher in DSS+CSR+ group mice. Pyruvate is a key metabolite of microbial cells , and the end product of glycolysis as well as the major metabolite of amino acid and protein metabolism. The acid could prevent hydrogen peroxide-induced apoptosis and enhance the metabolism of fatty acid[37, 38]. Fatty acid, with the effects of anti-inflammation and promoting autophagy, is obviously decreased in patients with UC. Moreover, indole-3-pyruvate was also proved to 
alleviate the inflammation of colon in experimental colitis mice[39]. L-ascorbate could attenuate endotoxin-induced production of inflammatory mediators by inhibiting MAPK activation and NF-kB translocation, the two signal pathways are activated in IBD[40]. It has also been reported that coordination of ENT2-dependent adenosine transport and signaling could dampen mucosal inflammation[41]. All in all, the upregulated pyruvate, L-ascorbate and adenosine might perform their anti-inflammatory effect in certain way in colitis.

In conclusion, our data demonstrated that CSR ameliorated colon inflammation in a gut microbiota-dependent manner. While the anti-inflammatory and immunosuppressive properties of CSR have been well described and discussed[21], its action on the gut microbiota was not studied. Thus, we can conclude that the underlying protective mechanism of therapeutic action of CSR is associated not only with rectifying the Treg/Th1 and Treg/Th17 balances and downregulation of inflammatory cytokine but with the modulation of microbiota-community structure and metabolisms as well. While the exact role of microbiome needs to be further investigated, this study still opens up a new direction in the study of traditional medicines.

\section{Methods}

\section{Animals}

All animal care and experimental procedures were approved by the Committee for Animal Research of Huazhong University of Science and Technology (Wuhan, China). Male BALB/c mice ( 8 weeks old, 18-22 g) were purchased from the experimental animal center of Huazhong University of Science and Technology (Wuhan, China). These animals were socially housed at relatively constant humidity (40-60\%), temperature $\left(22-24^{\circ} \mathrm{C}\right)$ and a 12-hours light/dark cycle and maintained on a normal chow diet with free access to water. All mice were allowed for 1 week housing before the experiment, and then randomly separated into three groups: normal control, DSS+, and DSS+CSR+. The acute experimental colitis model was induced according to previous publication[42]. Briefly, mice were administrated with 3.0\% (wt/vol) dextran 
sodium sulfate (DSS, MP Biomedicals, UK) supplemented in filter-purified drinking water for consecutive 7 days. After adaptive feeding, the DSS+CSR+ and DSS+ groups were performed for colitis induction, and administrated simultaneously with CSR (Chem Faces , Cat\# CFN99198) at a dose of $1 \mathrm{mg} \cdot \mathrm{kg}^{-1}$ and equal amount of saline by gavage daily for 7 days, respectively. Similarly, the normal control group were given distilled water with equal amounts of saline by gavage. During DSS treatment, the morbidity, body weights, stool consistency and stool occult blood of mice were daily monitored. The severity of colitis was measured by disease activity index (DAI) as described before[43]. The colon length was measured when the mice were were euthanized by excessive pentobarbital sodium.

\section{Depletion of the gut microbiota}

For the gut microbiota depletion experiment, mice were randomly divided into three groups: $\mathrm{ABX}+, \mathrm{ABX}+\mathrm{DSS}+$, and $\mathrm{ABX}+\mathrm{DSS}+\mathrm{CSR}+$. Mice in these three groups were treated with an antibiotic cocktail, including $1 \mathrm{~g} \cdot \mathrm{L}^{-1}$ ampicillin (Macklin), $1 \mathrm{~g} \cdot \mathrm{L}^{-1}$ neomycin (Sigma), $1 \mathrm{~g} \cdot \mathrm{L}^{-1}$ metronidazole (Sigma) and $0.5 \mathrm{~g} \cdot \mathrm{L}^{-1}$ vancomycin (Macklin), in drinking water for 3 weeks. Subsequently, the mice in ABX+DSS+ and $\mathrm{ABX}+\mathrm{DSS}+\mathrm{CSR}+$ groups were provided with DSS in drinking water, and mice in the $\mathrm{ABX}+\mathrm{DSS}+\mathrm{CSR}+$ group were treated with CSR $\left(1 \mathrm{mg} \cdot \mathrm{kg}^{-1}\right)$ orally once daily during DSS treatment whereas mice in other groups were treated with equal amount of saline.

\section{Fecal microbiota transplantation}

The fecal microbiota transplantation was performed based on the protocol as described before[44]. Briefly, donor mice were randomly divided into three groups including the DSS-CSR-, DSS+CSR-, and DSS+CSR+ groups. The DSS+CSR- and $\mathrm{DSS}+\mathrm{CSR}+$ groups received DSS diluted in drinking water to induce colitis. The $\mathrm{DSS}+\mathrm{CSR}+$ group received CSR treatment $\left(1 \mathrm{mg} \cdot \mathrm{kg}^{-1}\right)$ orally once per day whereas the DSS-CSR- and DSS+CSR- groups received saline. After 7 days, the stools from each donor group were collected daily under a laminar flow hood in sterile conditions. Then the samples were pooled, and $100 \mathrm{mg}$ was resuspended in $1 \mathrm{ml}$ of sterile saline. 
The solution was vigorously mixed for $10 \mathrm{~s}$ followed by centrifugation at $800 \mathrm{~g}$ for 3 min. Then the supernatant was collected and used as transplant material within $10 \mathrm{~min}$ by oral gavage to prevent changes in bacterial composition. Recipient mice were randomly divided into three groups. Each group of recipient mice received DSS treatment to induce colitis and simultaneously $200 \mathrm{ul}$ freshly prepared supernatant above per day for 7 days.

\section{Intestinal permeability assays}

Intestinal permeability was assessed by the fluorescein isothiocyanate conjugated dextran (FITC-dextran) tracer (4 kDa, Sigma-Aldrich, Cat\# 68059). Mice were fasted overnight and then administered with $0.5 \mathrm{ml}$ of FITC-dextran $\left(0.5 \mathrm{mg} \cdot \mathrm{g}^{-1}\right.$ body weight $)$ by oral gavage $4 \mathrm{~h}$ before being euthanized. Blood samples were collected at the time of euthanization, and the samples were centrifuged for $90 \mathrm{~s}$ at $6000 \mathrm{~g}$. FITC-dextran concentration was determined using fluorescence spectrometry at an excitation wavelength of $488 \mathrm{~nm}$ and emission wavelength of $520 \mathrm{~nm}$ within $5 \mathrm{~min}$ [45].

\section{Histopathology and Alcian blue staining}

The colons were emptied of fecal contents and opened longitudinally along the mesenteric border and formed a Swiss-Roll from the proximal to the distal end, then placed in $4 \%$ paraformaldehyde for 24 hours. The Swiss-Rolls were transferred to paraffin-embedded blocks to generate 5 - $\mu$ m-thick sections for hematoxylin and eosin (H\&E) staining and assessed blindly by a pathologist. The 5 - $\mu \mathrm{m}$-thick sections were also stained with Alcian blue periodic acid by standard techniques. Slices were visualized under a light microscope (Leica, Germany).

\section{Mouse colonic lamina propria lymphocytes (LPL) isolation}

Mouse colons were opened longitudinally and washed with cold PBS with 1M Hepes to remove the fecal contents. Pooled colons were cut into $0.5 \mathrm{~cm}$ pieces and washed with $25 \mathrm{ml}$ of HBSS (Gibco, Cat\# C14175500BT) containing 1M Hepes and $500 \mathrm{mM}$ EDTA on an orbital shaker at $100 \mathrm{rpm}$ for $25 \mathrm{~min}$ at $37{ }^{\circ} \mathrm{C}$. Then the colon pieces were washed twice using cold PBS with 1 M Hepes. After washing, the colons were finely cut and digested with $10 \mathrm{ml}$ RPMI 1640 (Gibco, Cat\# 11875-119) containing 
$1 \mathrm{mg} \cdot \mathrm{ml}^{-1}$ DNase I (Roche, Cat\# 10104159001), $0.5 \mathrm{mg} \cdot \mathrm{ml}^{-1}$ Type-D Collagenase (Roche, Cat\# 11088858001) at $100 \mathrm{rpm}$ for $15 \mathrm{~min}$ at $37^{\circ} \mathrm{C}$. After digestion, the colonic LP cells were filtered through $100 \mu \mathrm{m}$ strainer, followed by centrifugation at $1650 \mathrm{rpm}$ for $5 \mathrm{~min}$ at $4^{\circ} \mathrm{C}$, and resuspended on $500 \mu \mathrm{l}$ PBS for flow cytometric analysis[46].

\section{Flow cytometry}

Flow cytometry was performed as described previously[47]. Briefly, Single cell suspensions were stained with indicated antibodies diluted by PBS supplemented with $2 \%$ FBS and $0.5 \%$ BSA for surfaces markers. For the staining of intracellular

cytokines IFN- $\gamma$ and IL-17A, cells were incubated and stimulated with $200 \mathrm{ng} \cdot \mathrm{ml}^{-1}$ phorbol myristate acetate (PMA) (Enzo, Cat\# BML-PE160-0005), $1 \mu \mathrm{g} \cdot \mathrm{ml}^{-1}$ ionomycin (Enzo, Cat\# ALX-450-007-M001), $1 \mu \mathrm{g} \cdot \mathrm{ml}^{-1}$ brefeldin A (eBioscience, Cat\# 00-4506-51) at $37^{\circ} \mathrm{C}$ for $6 \mathrm{~h}$. Then, cultured cells were collected, washed and stained surface markers with CD45 and CD4 for $20 \mathrm{~min}$, followed by fixation and permeabilization, and then stained intracellularly with anti-IFN- $\gamma$ and anti-IL-17A antibody for 30 min. For Foxp3, T-bet and ROR- $\gamma$ t staining, the cells were stained for surface marker such as CD45 and CD4, followed by fixation and permeabilization with fixation and permeabilization buffer (Thermo Fisher Scientific, Cat\# 88-8824-00) at room temperature for $30 \mathrm{~min}$. After washes, the cells were then stained with anti-Foxp3, anti-T-bet or anti-ROR- $\gamma$ t antibody as instructed. All samples were detected by CytoFLEX LX Flow Cytometry System and analyzed with the CytExpert 2.0 Software. Antibodies used for flow cytometry included anti-mouse CD45-FITC (BD Biosciences, Cat\# 553080), CD4-PE/Cy7 (BD Biosciences, Cat\# 552775), IL-17A-PE (BD Biosciences, Cat\# 561020), IFN- $\gamma$-APC (BD Biosciences, Cat\# 562018), ROR- $\gamma t-B V 421$ (BD Biosciences, Cat\# 562894), Foxp3-PE (Thermo Fisher Scientific, Cat\# 12-5773-82), T-bet-APC (BD Biosciences, Cat\# 561264), and Fixable Viability Stain 510 (BD Biosciences, Cat\# 564406). Flow gating strategies for each cell population were showed in Figure S7.

\section{Quantitative real-time polymerase chain reaction (qRT-PCR) for mRNA}


Total RNA was extracted from colonic tissues using RNAiso Plus (TaKaRa, Cat\# 9109 ) according to the manufacturer's protocols. After isolation of RNA, PrimeScript RT Master Mix (TaKaRa, Cat\# RR036A) were used to generate complementary DNAs (cDNAs) of mRNAs. Then, these cDNAs were analyzed to explore genes expression changes by SYBR Premix Ex Taq (TaKaRa, Cat\# RR420A). The relative expression levels of genes in tissues were normalized to $\beta$-actin. The sequences of all primers are listed in Table 1.

\section{Fecal genomic DNA extraction and 16S-rRNA sequencing}

Fecal genomic DNA extraction and 16S-rRNA sequencing were performed at Novogene (Beijing, China). Total genome DNA from fecal samples was extracted using CTAB/SDS method. DNA concentration and purity were monitored on $1 \%$ agarose gels. According to the concentration, DNA was diluted into $1 \mathrm{ng} \cdot \mu^{-1}$ using sterile water. 16S rRNA genes of distinct regions (16S V3-V4) were amplified used specific primer with the barcode. All PCR reactions were carried out with Phusion ${ }^{\circledR}$ High-Fidelity PCR Master Mix (New England Biolabs). Mix same volume of $1 \times$ loading buffer (contained SYBR green) with PCR products and operate electrophoresis on $2 \%$ agarose gel for detection. PCR products was mixed in equidensity ratios. Then, mixture PCR products was purified with GeneJET ${ }^{\mathrm{TM}}$ Gel Extraction Kit (Thermo Fisher Scientific). Sequencing libraries were generated using Ion Plus Fragment Library Kit 48 rxns (Thermo Fisher Scientific) following manufacturer's recommendations. The library quality was assessed on the Qubit@ 2.0 Fluorometer (Thermo Fisher Scientific). At last, the library was sequenced on an Ion $\mathrm{S}^{\mathrm{TM}}$ XL platform and $600 \mathrm{bp}$ single-end reads were generated.

\section{Untargeted metabolomics analysis}

Untargeted metabolomics analysis were performed at Novogene (Beijing, China). Fecal samples $(100 \mathrm{mg})$ were individually grounded with liquid nitrogen and the homogenate was resuspended with prechilled $80 \%$ methanol and $0.1 \%$ formic acid by fully vortexing. The samples were incubated on ice for $5 \mathrm{~min}$ and then were centrifuged at $15000 \mathrm{rpm}, 4^{\circ} \mathrm{C}$ for $5 \mathrm{~min}$. And then, the supernatant was diluted to 
final concentration containing 53\% methanol by LC-MS grade water. The samples were subsequently transferred to a fresh Eppendorf tube and then were centrifuged at $15000 \mathrm{~g}, 4^{\circ} \mathrm{C}$ for $10 \mathrm{~min}$. Finally, the supernatant was injected into the LC-MS system analysis.

\section{Isolation of naïve $\mathrm{CD4}^{+} \mathrm{T}$ cells and in vitro induction of differentiation}

Total spleen $\mathrm{T}$ cells were purified by negative selection with the mouse naïve $\mathrm{CD} 4^{+} \mathrm{T}$ Cells Isolation Kit (Miltenyi Biotec, Cat\# 130-104-453) and LS separation columns (Miltenyi Biotec, Cat\# 130-042-401) following the manufacturer's instructions. Naive $\mathrm{CD}^{+} \mathrm{T}$ cells were seeded in 96-well plates coated with anti-CD3 (Thermo Fisher Scientific, Cat\# 16-0032-85) and anti-CD28 (Thermo Fisher Scientific, Cat\# 16-0281-85) antibodies at $2 \times 10^{5}$ cells/well in RPMI 1640 medium (Gibco, Cat\# 11875-119) containing 10\% inactivated fetal bovine serum (Gibco, Cat\# 10099141).

For Th1 cell differentiation, naïve $\mathrm{CD}^{+} \mathrm{T}$ cells were cultured with $10 \mathrm{ng} \cdot \mathrm{ml}^{-1} \mathrm{IL}-12$ (R\&D, Cat\# 402-ML-020/CF) and $10 \mu \mathrm{g} \cdot \mathrm{ml}^{-1}$ anti-IL-4 (Bio X Cell, Cat\# BE0045, RRID:AB_1107707). For Th17 cell differentiation, naive CD4 ${ }^{+} \mathrm{T}$ cells were cultured with $2 \mathrm{ng} \cdot \mathrm{ml}^{-1}$ TGF- $\beta$ (R\&D, Cat\# 240-B-002/CF), $10 \mathrm{ng} \cdot \mathrm{ml}^{-1}$ IL-6 (R\&D, Cat\# 406-ML-005/CF), $10 \mu \mathrm{g} \cdot \mathrm{ml}^{-1} \quad$ anti-IFN- $\gamma \quad$ (Bio $\quad X \quad$ Cell, Cat\# BE0055, RRID:AB_1107694), $10 \mu \mathrm{g} \cdot \mathrm{ml}^{-1}$ anti-IL-4 and $10 \mu \mathrm{g} \cdot \mathrm{ml}^{-1}$ anti-IL-2 (Bio X Cell, Cat\# BE0043-1, RRID:AB_1107705). For Treg cell differentiation, naive CD4 ${ }^{+} \mathrm{T}$ cells were cultured with $2 \mathrm{ng} \cdot \mathrm{ml}^{-1}$ TGF- $\beta$.

The effects of different concentrations of CSR , pyruate (Macklin, Cat\# P6033) and adenosine (Macklin, Cat\# A6218) on the differentiation of Th1, Th17 and Treg were assessed by flow cytometry after $72 \mathrm{~h}$ culture.

\section{Data and analysis}

All experiments were designed to generate groups of equal size, using randomization and blind data analysis, and no data points were excluded from the analysis in any experiment. The data of qRT-PCR were normalized to control to avoid unwanted sources of variation. The statistical analysis was undertaken only for studies where each group size was at least $\mathrm{n}=5$. Data are presented as mean $\pm S E M$, and statistic 
were analysed with GraphPad Prism (GraphPad Prism version 6.0). Student's $t$-tests were used to compare the means of two groups. And comparisons among multiple groups were performed with one-way ANOVA with Tukey's test. Post hoc tests were run only if $\mathrm{F}$ achieved $P<0.05$, and there was no significant variance inhomogeneity. $P$-values $<0.05$ were considered statistically significant. The declare group size is the number of independent values, and statistical analysis was performed using these independent values (technical replicates were not treated as independent values).

\section{Author contribution}

Fan Heng : Project administration. Li Mingyue, Tian Chunxia, Gui Yang and Dong Yalan: Conceptualization, Formal analysis, Methodology, Investigation, Software, Writing-original draft. Yu Ting, Guo Weina, Wang Wenzhu and Zhang Zili: Validation. Xue Kaming and Jiang Feng: Date curation. Li Junyi, Zhou Haifeng and Alexey Sarapultsev: Methodology. Hu Desheng and Luo Shanshan: Supervision, Funding acquisition.

\section{Disclosure of interest}

The authors declare no conflict of interest.

\section{Acknowledgments}

This study was funded by the grants from the National Key R\&D Program of China (2019YFC1316204), and the National Natural Science Foundation of China (Nos. 81974249, 31770983, 82070136), and the Hubei Provincial Natural Science Foundation of China (No.2020BHB016). 
References

1. Kaplan GG, Ng SC: Understanding and Preventing the Global Increase of Inflammatory Bowel Disease. Gastroenterology 2017, 152:313-321.e312.

2. Ng SC, Shi HY, Hamidi N, Underwood FE, Tang W, Benchimol El, Panaccione R, Ghosh S, Wu JCY, Chan FKL, et al: Worldwide incidence and prevalence of inflammatory bowel disease in the 21 st century: a systematic review of population-based studies. Lancet 2018, 390:2769-2778.

3. Harbord M, Eliakim R, Bettenworth D, Karmiris K, Katsanos K, Kopylov U, Kucharzik T, Molnár T, Raine T, Sebastian S, et al: Third European Evidence-based Consensus on Diagnosis and Management of Ulcerative Colitis. Part 2: Current Management. $J$ Crohns Colitis 2017, 11:769-784.

4. Rubin DT, Ananthakrishnan AN, Siegel CA, Sauer BG, Long MD: ACG Clinical Guideline: Ulcerative Colitis in Adults. Am J Gastroentero/2019, 114:384-413.

5. Kobayashi T, Siegmund B, Le Berre C, Wei SC, Ferrante M, Shen B, Bernstein CN, Danese S, Peyrin-Biroulet L, Hibi T: Ulcerative colitis. Nat Rev Dis Primers 2020, 6:74.

6. Kaser A, Zeissig S, Blumberg RS: Inflammatory bowel disease. Annu Rev Immunol 2010, 28:573-621.

7. Himmel ME, Hardenberg G, Piccirillo CA, Steiner TS, Levings MK: The role of T-regulatory cells and Toll-like receptors in the pathogenesis of human inflammatory bowel disease. Immunology 2008, 125:145-153. 
8. Bedoya SK, Lam B, Lau K, Larkin J, 3rd: Th17 cells in immunity and autoimmunity. Clin Dev Immunol 2013, 2013:986789.

9. Benedetti G, Miossec P: Interleukin 17 contributes to the chronicity of inflammatory diseases such as rheumatoid arthritis. Eur J Immuno/2014, 44:339-347.

10. Brand S: Crohn's disease: Th1, Th17 or both? The change of a paradigm: new immunological and genetic insights implicate Th17 cells in the pathogenesis of Crohn's disease. Gut 2009, 58:1152-1167.

11. Luo A, Leach ST, Barres R, Hesson LB, Grimm MC, Simar D: The Microbiota and Epigenetic Regulation of T Helper 17/Regulatory T Cells: In Search of a Balanced Immune System. Front Immuno/2017, 8:417.

12. Tillack C, Ehmann LM, Friedrich M, Laubender RP, Papay P, Vogelsang H, Stallhofer J, Beigel F, Bedynek A, Wetzke M, et al: Anti-TNF antibody-induced psoriasiform skin lesions in patients with inflammatory bowel disease are characterised by interferon-Y-expressing Th1 cells and IL-17A/IL-22-expressing Th17 cells and respond to anti-IL-12/IL-23 antibody treatment. Gut 2014, 63:567-577.

13. Wang $\mathrm{X}, \mathrm{Ma} \mathrm{C}, \mathrm{Wu} \mathrm{J}$, Zhu J: Roles of $\mathrm{T}$ helper 17 cells and interleukin-17 in neuroautoimmune diseases with emphasis on multiple sclerosis and Guillain-Barré syndrome as well as their animal models. J Neurosci Res 2013, 91:871-881.

14. Britton GJ, Contijoch EJ, Mogno I, Vennaro OH, Llewellyn SR, Ng R, Li Z, Mortha A, Merad M, Das A, et al: Microbiotas from Humans with Inflammatory Bowel Disease Alter the Balance of Gut Th17 and RORyt(+) Regulatory T Cells and Exacerbate Colitis in Mice. Immunity 2019, 50:212-224.e214. 
15. Vujkovic-Cvijin I, Sklar J, Jiang L, Natarajan L, Knight R, Belkaid Y: Host variables confound gut microbiota studies of human disease. Nature 2020, 587:448-454.

16. Franzosa EA, Sirota-Madi A, Avila-Pacheco J, Fornelos N, Haiser HJ, Reinker S, Vatanen $T$, Hall $A B$, Mallick $H$, Mclver LJ, et al: Gut microbiome structure and metabolic activity in inflammatory bowel disease. Nat Microbio/2019, 4:293-305.

17. Halfvarson J, Brislawn CJ, Lamendella R, Vázquez-Baeza Y, Walters WA, Bramer LM, D'Amato M, Bonfiglio F, McDonald D, Gonzalez A, et al: Dynamics of the human gut microbiome in inflammatory bowel disease. Nat Microbio/2017, 2:17004.

18. Gonçalves P, Araújo JR, Di Santo JP: A Cross-Talk Between Microbiota-Derived Short-Chain Fatty Acids and the Host Mucosal Immune System Regulates Intestinal Homeostasis and Inflammatory Bowel Disease. Inflamm Bowel Dis 2018, 24:558-572.

19. Lavelle A, Sokol H: Gut microbiota-derived metabolites as key actors in inflammatory bowel disease. Nat Rev Gastroenterol Hepatol2020, 17:223-237.

20. Smith PM, Howitt MR, Panikov N, Michaud M, Gallini CA, Bohlooly YM, Glickman JN, Garrett WS: The microbial metabolites, short-chain fatty acids, regulate colonic Treg cell homeostasis. Science 2013, 341:569-573.

21. Cascão R, Fonseca JE, Moita LF: Celastrol: A Spectrum of Treatment Opportunities in Chronic Diseases. Front Med (Lausanne) 2017, 4:69.

22. Shaker ME, Ashamallah SA, Houssen ME: Celastrol ameliorates murine colitis via modulating oxidative stress, inflammatory cytokines and intestinal homeostasis. Chem Biol Interact 2014, 210:26-33.

23. Jia Z, Xu C, Shen J, Xia T, Yang J, He Y: The natural compound celastrol inhibits 
necroptosis and alleviates ulcerative colitis in mice. Int Immunopharmaco/ 2015, 29:552-559.

24. Chassaing B, Aitken JD, Malleshappa M, Vijay-Kumar M: Dextran sulfate sodium (DSS)-induced colitis in mice. Curr Protoc Immuno/2014, 104:15.25.11-15.25.14.

25. Taghipour N, Molaei M, Mosaffa N, Rostami-Nejad M, Asadzadeh Aghdaei H, Anissian A, Azimzadeh P, Zali MR: An experimental model of colitis induced by dextran sulfate sodium from acute progresses to chronicity in C57BL6: correlation between conditions of mice and the environment. Gastroenterol Hepatol Bed Bench 2016, 9:45-52.

26. Venkatesha $\mathrm{SH}$, Moudgil KD: Celastrol suppresses experimental autoimmune encephalomyelitis via MAPKISGK1-regulated mediators of autoimmune pathology. Inflamm Res 2019, 68:285-296.

27. Astry B, Venkatesha SH, Laurence A, Christensen-Quick A, Garzino-Demo A, Frieman MB, O'Shea JJ, Moudgil KD: Celastrol, a Chinese herbal compound, controls autoimmune inflammation by altering the balance of pathogenic and regulatory $\mathrm{T}$ cells in the target organ. Clin Immuno/2015, 157:228-238.

28. Hold GL, Smith M, Grange C, Watt ER, EI-Omar EM, Mukhopadhya I: Role of the gut microbiota in inflammatory bowel disease pathogenesis: what have we learnt in the past 10 years? World J Gastroentero/2014, 20:1192-1210.

29. Tremaroli V, Bäckhed F: Functional interactions between the gut microbiota and host metabolism. Nature 2012, 489:242-249.

30. Gionchetti P, Rizzello F, Venturi A, Brigidi P, Matteuzzi D, Bazzocchi G, Poggioli G, 
Miglioli M, Campieri M: Oral bacteriotherapy as maintenance treatment in patients with chronic pouchitis: a double-blind, placebo-controlled trial. Gastroenterology2000, 119:305-309.

31. Grimm V, Riedel CU: Manipulation of the Microbiota Using Probiotics. Adv Exp Med Bio/2016, 902:109-117.

32. Haifer C, Leong RW, Paramsothy S: The role of faecal microbiota transplantation in the treatment of inflammatory bowel disease. Curr Opin Phamacol2020, 55:8-16.

33. Parada Venegas D, De la Fuente MK, Landskron G, González MJ, Quera R, Dijkstra G, Harmsen HJM, Faber KN, Hermoso MA: Short Chain Fatty Acids (SCFAs)-Mediated Gut Epithelial and Immune Regulation and Its Relevance for Inflammatory Bowel Diseases. Front Immuno/2019, 10:277.

34. Huang $\mathrm{K}$, Dong $\mathrm{W}$, Liu W, Yan $\mathrm{Y}$, Wan $\mathrm{P}$, Peng $\mathrm{Y}, \mathrm{Xu} \mathrm{Y}$, Zeng $\mathrm{X}$, Cao $\mathrm{Y}$ : 2-O- $\beta$-d-Glucopyranosyl-I-ascorbic Acid, an Ascorbic Acid Derivative Isolated from the Fruits of Lycium Barbarum L., Modulates Gut Microbiota and Palliates Colitis in Dextran Sodium Sulfate-Induced Colitis in Mice. J Agric Food Chem 2019, 67:11408-11419.

35. Kelly TN, Bazzano LA, Ajami NJ, He H, Zhao J, Petrosino JF, Correa A, He J: Gut Microbiome Associates With Lifetime Cardiovascular Disease Risk Profile Among Bogalusa Heart Study Participants. Circ Res 2016, 119:956-964.

36. Huda-Faujan N, Abdulamir AS, Fatimah AB, Anas OM, Shuhaimi M, Yazid AM, Loong YY: The impact of the level of the intestinal short chain Fatty acids in inflammatory bowel disease patients versus healthy subjects. Open Biochem J2010, 4:53-58. 
37. Kamzolova SV, Morgunov IG: Biosynthesis of pyruvic acid from glucose by Blastobotrys adeninivorans. App/ Microbiol Biotechno/2016, 100:7689-7697.

38. Ramakrishnan N, Chen R, McClain DE, Bünger R: Pyruvate prevents hydrogen peroxide-induced apoptosis. Free Radic Res 1998, 29:283-295.

39. Aoki R, Aoki-Yoshida A, Suzuki C, Takayama Y: Indole-3-Pyruvic Acid, an Aryl Hydrocarbon Receptor Activator, Suppresses Experimental Colitis in Mice. J /mmuno/ 2018, 201:3683-3693.

40. Huang YN, Lai CC, Chiu CT, Lin JJ, Wang JY: L-ascorbate attenuates the endotoxin-induced production of inflammatory mediators by inhibiting MAPK activation and NF-KB translocation in cortical neurons/glia Cocultures. PLOS One 2014, 9:e97276.

41. Aherne CM, Collins CB, Rapp CR, Olli KE, Perrenoud L, Jedlicka P, Bowser JL, Mills TW, Karmouty-Quintana H, Blackburn MR, Eltzschig HK: Coordination of ENT2-dependent adenosine transport and signaling dampens mucosal inflammation. JCl Insight 2018, 3.

42. Wirtz S, Popp V, Kindermann M, Gerlach K, Weigmann B, Fichtner-Feigl S, Neurath MF: Chemically induced mouse models of acute and chronic intestinal inflammation. Nat Protoc 2017, 12:1295-1309.

43. Yang J, Liu XX, Fan H, Tang Q, Shou ZX, Zuo DM, Zou Z, Xu M, Chen QY, Peng Y, et al: Extracellular Vesicles Derived from Bone Marrow Mesenchymal Stem Cells Protect against Experimental Colitis via Attenuating Colon Inflammation, Oxidative Stress and Apoptosis. PLoS One 2015, 10:e0140551. 
44. Cui H, Cai Y, Wang L, Jia B, Li J, Zhao S, Chu X, Lin J, Zhang X, Bian Y, Zhuang P:

Berberine Regulates Treg/Th17 Balance to Treat Ulcerative Colitis Through

Modulating the Gut Microbiota in the Colon. Front Phamacol2018, 9:571.

45. Ma X, Sun Q, Sun X, Chen D, Wei C, Yu X, Liu C, Li Y, Li J: Activation of GABA(A)

Receptors in Colon Epithelium Exacerbates Acute Colitis. Front Immuno/2018, 9:987.

46. Ivanov, II, McKenzie BS, Zhou L, Tadokoro CE, Lepelley A, Lafaille JJ, Cua DJ, Littman DR: The orphan nuclear receptor RORgammat directs the differentiation program of proinflammatory IL-17+ T helper cells. Cel/2006, 126:1121-1133.

47. Ji J, Ge X, Chen Y, Zhu B, Wu Q, Zhang J, Shan J, Cheng H, Shi L: Daphnetin ameliorates experimental colitis by modulating microbiota composition and T(reg)/T(h)17 balance. Faseb j2019, 33:9308-9322.

\section{Figure legends}

Figure 1. CSR attenuated DSS-induced experimental colitis in mice.

(A) Schematic diagram illustrates the experimental design. (B) Body weight percentage changes of each group $(n=10)$. (C) Measurement of the length of colons harvested from mice in each group $(n=10)$. (D) The effect of CSR on DAI in mice $(n=10)$. (E) Mice in each group received an oral gavage of FITC-dextran $(0.5 \mathrm{mg} / \mathrm{g})$ and serum FITC-dextran concentrations were determined $4 \square \mathrm{h}$ later (n=5). (F) H\&E staining (Bar=1mm above, Bar=100um below) sections and histological scores of colon tissue from mice in each group $(\mathrm{n}=5)$. (G) The expression levels of Occludin, Cdh1, Zo-1 and Muc2 of colon tissue in each group (n=5). (H) The expression levels of pro-inflammatory cytokines of colon tissue in each group (n=5). (I) The expression levels of anti-inflammatory cytokines of colon tissue in each group $(n=5)$. (J) T-bet $^{+} \mathrm{CD} 4^{+}$(Th1) cells and ROR- $\gamma \mathrm{t}^{+} \mathrm{CD} 4^{+}$(Th17) cells in spleen, MLN and LPL from the control, DSS+ group and DSS+CSR+ group were analyzed by flow cytometry and 
bar charts of the percentage of Th1 and Th17 cells (n=5). (K) Foxp $3^{+} \mathrm{CD} 4^{+}$(Treg) cells in spleen, MLN and LPL from the control, DSS+ group and DSS+CSR+ group were analyzed by flow cytometry and bar charts of the percentage of Treg cells $(n=5)$. Data are presented as mean $\pm S E M$. $* P<0.05$, significantly different as indicated.

Figure 2. Effects of CSR against DSS-induced colitis after pretreatment with ABX.

(A) Schematic diagram illustrates the experimental design. (B) Body weight percentage changes of each group. (C) Measurement of the length of colons harvested from mice in each group $(n=10)$. (D) The effect of CSR on DAI in mice $(n=10)$. (E) Mice in each group received an oral gavage of FITC-dextran $(0.5 \mathrm{mg} / \mathrm{g})$ and serum FITC-dextran concentrations were determined $4 \square \mathrm{h}$ later $(\mathrm{n}=5)$. (F) H\&E staining (Bar=1mm above, Bar=100um below) sections and histological scores of colon tissue from mice in each group $(\mathrm{n}=5)$. (G) The expression levels of Occludin, Cdh1, ZO-1 and MUC2 of colon tissue in each group $(n=5)$. (H) The expression levels of pro-inflammatory cytokines of colon tissue in each group $(n=5)$. (I) The expression levels of anti-inflammatory cytokines of colon tissue in each group $(n=5)$. (J) $\mathrm{T}^{-b e t}{ }^{+} \mathrm{CD} 4^{+}(\mathrm{Th} 1)$ cells and ROR- $\gamma \mathrm{t}^{+} \mathrm{CD} 4^{+}$(Th17) cells in spleen, MLN and LPL from the $\mathrm{ABX}+$ group, $\mathrm{ABX}+\mathrm{DSS}+$ group and $\mathrm{ABX}+\mathrm{DSS}+\mathrm{CSR}+$ group were analyzed by flow cytometry and bar charts of the percentage of Th1 and Th17 cells $(n=5)$. (K) Foxp $3^{+} \mathrm{CD}^{+}$(Treg) cells in spleen, MLN and LPL from ABX+ group, ABX+DSS+ group and $\mathrm{ABX}+\mathrm{DSS}+\mathrm{CSR}+$ group were analyzed by flow cytometry and bar charts of the percentage of Treg cells $(\mathrm{n}=5)$. Data are presented as mean $\pm S E M$. $* P<0.05$, significantly different as indicated.

Figure 3. Fecal transplants from CSR-treated mice confer the protection for colitic mice.

(A) Schematic diagram illustrates the experimental design. (B) Body weight percentage changes of each group. (C) Measurement of the length of colons harvested from mice in each group ( $n=10)$. (D) The effect of CSR on DAI in mice $(n=10)$. (E) Mice in each group received an oral gavage of FITC-dextran $(0.5 \mathrm{mg} / \mathrm{g})$ and serum 
FITC-dextran concentrations were determined $4 \square \mathrm{h}$ later $(\mathrm{n}=5)$. (F) H\&E staining (Bar=1mm above, Bar=100um below) sections and histological scores of colon tissue from mice in each group $(\mathrm{n}=5)$. (G) The expression levels of Occludin, Cdh1, ZO-1 and MUC2 of colon tissue in each group $(n=5)$. (H) The expression levels of pro-inflammatory cytokines of colon tissue in each group $(n=5)$. (I) The expression levels of anti-inflammatory cytokines of colon tissue in each group $(n=5)$. (J) T-bet $^{+} \mathrm{CD} 4^{+}$(Th1) cells and ROR- $\gamma \mathrm{t}^{+} \mathrm{CD} 4^{+}$(Th17) cells in spleen, MLN and LPL from DSS-CSR- group, DSS+CSR- group and DSS+CSR+ group were analyzed by flow cytometry and bar charts of the percentage of Th1 and Th17 cells $(n=5)$. (K) Foxp $3^{+} \mathrm{CD}^{+}$(Treg) cells in spleen, MLN and LPL from the DSS-CSR-group, DSS+CSR- group and DSS+CSR+ group were analyzed by flow cytometry and bar charts of the percentage of Treg cells $(\mathrm{n}=5)$. Data are presented as mean $\pm S E M$. $* P<$ 0.05 , significantly different as indicated.

\section{Figure 4. CSR treatment significantly altered the gut microbiota diversity and} composition.

(A) Alpha diversity boxplot (observed species, Chao1, ace and PD-whole tree). (B) Principal coordinate analysis (PCoA) using Binary-Jaccard and Unweighted-UniFrad of beta diversity. (C) Taxonomic cladogram from LEfSe, depicting taxonomic association from between microbiome communities from the control, DSS+ and DSS+CSR+ groups. (D) LDA score computed from features differentially abundant between the control, DSS+ and DSS+CSR+ groups. (E) Heatmap of selected most differentially abundant features at the genus level. The blue color represents less abundant, white color represents intermediate abundance and red represents the most abundant. Each symbol represents an individual mouse.

\section{Figure 5. CSR treatment significantly alter metabolomics.}

(A) Partial least-squares discrimination analysis (PLS-DA) of metabolomic profile. (B) Hierarchical clustering of metabolites. (C) Relative concentration of metabolites under negative ion mode in DSS+ group and DSS+CSR+ group. (D) Relative concentration of metabolites under positive ion in DSS + group and DSS $+\mathrm{CSR}+$ group. 
Data are pooled in one independent experiment and presented as mean $\pm S E M$. ${ }^{*} P<$ 0.05 , significantly different as indicated.

Figure 6. The influence of pyruate and adenosine treatment on $T$ cell differentiation in vitro.

Spleen naive $\mathrm{CD}^{+}{ }^{\mathrm{T}}$ cells from C57BL/6 were cultured under Th1, Th17 and Treg skewing condition in the presence or absence of pyruate or adenosine respectively. (A) A plot from one representative experiment displays the proportions of $\mathrm{IFN}-\gamma^{+} \mathrm{CD} 4^{+}$ (Th1) cells, and the mean proportions of Th1 cells were analyzed by bar chart. (B) A plot from one representative experiment displays the proportions of $\mathrm{IL}-17 \mathrm{~A}^{+} \mathrm{CD} 4^{+}$ (Th17) cells, and the mean proportions of Th17 cells were analyzed by bar chart. (C) A plot from one representative experiment displays the proportions of Foxp $3^{+} \mathrm{CD} 4^{+}$ (Treg) cells, and the mean proportions of Treg cells were analyzed by bar chart. Data are presented as mean $\pm S E M$. $* P<0.05$, significantly different as indicated.

Figure 7. Schematic depiction about the protective effects of celastrol during ulcerative colitis.

\section{Supplementary material}

\section{Figure S1. CSR attenuated DSS-induced experimental colitis in mice.}

(A) The molecular structure of CSR. (B) Alcian blue staining (Bar=100um) sections of colon tissue from mice in each group (n=5). (C) IFN $-\gamma^{+} \mathrm{CD} 4^{+}$(Th1) cells and IL-17A ${ }^{+} \mathrm{CD}^{+}$(Th17) cells in spleen and MLN from the control, DSS+ group and DSS+CSR+ group were analyzed by flow cytometry and bar charts of the percentage of Th1 and Th17 cells $(\mathrm{n}=5)$. Data are presented as mean $\pm S E M$. ${ }^{*} P<0.05$, significantly different as indicated.

\section{Figure S2. The influence of celastrol treatment on $\mathbf{T}$ cell differentiation in vitro.}

Spleen naive $\mathrm{CD}^{+} \mathrm{T}$ cells from C57BL/6 were cultured under Th1, Th17 and Treg skewing condition in the presence or absence of CSR respectively. (A) A plot from one representative experiment displays the proportions of IFN- $\gamma^{+} \mathrm{CD} 4^{+}$(Th1) cells, and the mean proportions of Th1 cells were analyzed by bar chart. (B) A plot from 
one representative experiment displays the proportions of $\mathrm{IL}-17 \mathrm{~A}^{+} \mathrm{CD} 4^{+}$(Th17) cells, and the mean proportions of Th17 cells were analyzed by bar chart. (C) A plot from one representative experiment displays the proportions of Foxp $3^{+} \mathrm{CD} 4^{+}$(Treg) cells, and the mean proportions of Treg cells were analyzed by bar chart. Data are presented as mean $\pm S E M$. $* P<0.05$, significantly different as indicated.

\section{Figure S3. General changes of mice after antibiotics treatment.}

(A) $\mathrm{ABX}$ treatment altered the total DNA and the structure of gut microbiota in fecal samples of mice $(n=5)$. (B) H\&E staining indicated the antibiotics treatment could not affecte the morphology of liver (Bar=50um), kidney (Bar=50um), and colon (Bar=100um) (n=5); (C) Serum ALT, AST, BUN and CRE levels were not changed after antibiotics treatment $(\mathrm{n}=5)$. Data are presented as mean \pm SEM. $* P<0.05$, significantly different as indicated.

Figure S4. Effects of CSR against DSS-induced colitis after pretreatment with ABX.

(A) Alcian blue staining (Bar=100um) sections of colon tissue from mice in each

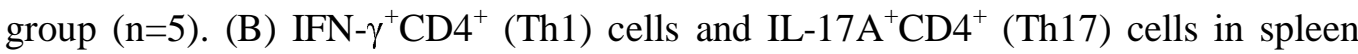
and MLN from the $\mathrm{ABX}+$ group, $\mathrm{ABX}+\mathrm{DSS}+$ group and $\mathrm{ABX}+\mathrm{DSS}+\mathrm{CSR}+$ group were analyzed by flow cytometry and bar charts of the percentage of Th1 and Th17 cells $(\mathrm{n}=5)$. Data are presented as mean $\pm S E M . * P<0.05$, significantly different as indicated.

Figure S5. Fecal transplants from CSR-treated mice confer the protection for colitic mice.

(A) Alcian blue staining (Bar=100um) sections of colon tissue from mice in each group ( $\mathrm{n}=5)$. (B) $\mathrm{IFN}-\gamma^{+} \mathrm{CD} 4^{+}$(Th1) cells and IL-17A ${ }^{+} \mathrm{CD} 4^{+}$(Th17) cells in spleen and MLN from DSS-CSR- group, DSS+CSR- group and DSS+CSR+ group were analyzed by flow cytometry and bar charts of the percentage of Th1 and Th17 cells $(\mathrm{n}=5)$. Data are presented as mean $\pm S E M$. $* P<0.05$, significantly different as indicated.

Figure S6. CSR treatment significantly altered the gut microbiota diversity and 


\section{composition.}

(A) Bar plots of the phylum taxonomic levels in control, DSS+ group and DSS+CSR+ group. Relative abundance is plotted for each sample. The relative abundances of Bacteroidetes and Firmicutes, and the ratio of Firmicutes to Bacteroidetes (F/B). (B) Bar plots of the class taxonomic levels in control, DSS+ group and DSS+CSR+ group. Relative abundance is plotted for each sample. (C) Bar plots of the order taxonomic levels in control, DSS+ group and DSS+CSR+ group. Relative abundance is plotted for each sample. (D) Bar plots of the family taxonomic levels in control, DSS+ group and DSS+CSR+ group. Relative abundance is plotted for each sample. (E) Bar plots of the genus taxonomic levels in control, DSS+ group and DSS+CSR+ group. Relative abundance is plotted for each sample. (F) Relative abundance of genus Odoribacter, Alloprevotella and unidentified_Lachnospiraceae in each sample were displayed by bar plots.

Figure S7. Flow gating strategies for each cell population.

Table 1. Primer sequences of target genes for mice.

\begin{tabular}{|c|c|c|}
\hline Genes & & Primer sequences $\left(5^{\prime}-3^{\prime}\right)$ \\
\hline \multirow[t]{2}{*}{$\beta$-actin } & sense & GTGACGTTGACATCCGTAAAGA \\
\hline & Anti-sense & GTAACAGTCCGCCTAGAAGCAC \\
\hline \multirow[t]{2}{*}{$I l-1 \beta$} & sense & GGGCCTCAAAGGAAAGAATC \\
\hline & Anti-sense & TACCAGTTGGGGAACTCTGC \\
\hline \multirow[t]{2}{*}{ Il-17a } & sense & ATGAGTGCCGACAAACAACG \\
\hline & Anti-sense & TTCTGCCATCTCCTCAGCCT \\
\hline \multirow[t]{2}{*}{ Ifn- $\gamma$} & sense & CTCAAGTGGCATAGATGTGGAAG \\
\hline & Anti-sense & TGACCTCAAACTTGGCAATACTC \\
\hline \multirow[t]{2}{*}{ Il-6 } & sense & ССССААТTТССААТGСТСТСС \\
\hline & Anti-sense & CGCACTAGGTTTGCCGAGTA \\
\hline \multirow[t]{2}{*}{$\operatorname{Tnf}-\alpha$} & sense & TGTCTCAGCCTCTTCTCATTCC \\
\hline & Anti-sense & CAGACACTCACСТCATCССТTT \\
\hline \multirow[t]{2}{*}{$T g f-\beta$} & sense & CCTGCTAATGTTGTTGCCC \\
\hline & Anti-sense & AGTAGGCAGCATCCAAAGC \\
\hline \multirow[t]{2}{*}{ Il-10 } & sense & TAATAAGCTCCAAGACCAAG \\
\hline & Anti-sense & TAGAATGGGAACTGAGGTATC \\
\hline \multirow[t]{2}{*}{ Occludin } & sense & TGGCAAGCGATCATACCCAGAG \\
\hline & Anti-sense & CTGCCTGAAGTCATCCACACTC \\
\hline \multirow[t]{2}{*}{ Cdhl } & sense & GGTCATCAGTGTGCTCACCTCT \\
\hline & Anti-sense & GCTGTTGTGCTCAAGCCTTCAC \\
\hline
\end{tabular}


bioRxiv preprint doi: https://doi.org/10.1101/2021.09.28.462065; this version posted September 28, 2021. The copyright holder for this preprint (which was not certified by peer review) is the author/funder. All rights reserved. No reuse allowed without permission.

\begin{tabular}{lll}
\hline Zo-1 & sense & GTTGGTACGGTGCCCTGAAAGA \\
& Anti-sense & GCTGACAGGTAGGACAGACGAT \\
Muc2 & sense & TCCTGACCAAGAGCGAACAC \\
& Anti-sense & GGGTAGGGTCACCTCCATCT \\
\hline
\end{tabular}


A
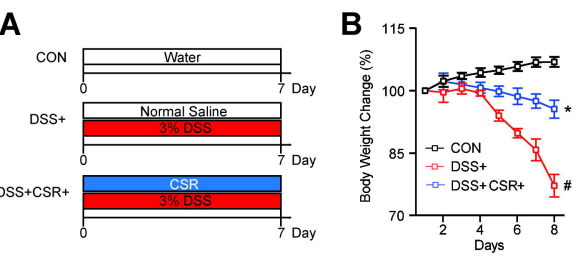

C

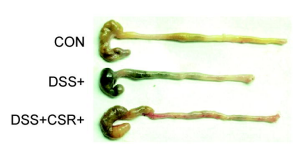

D

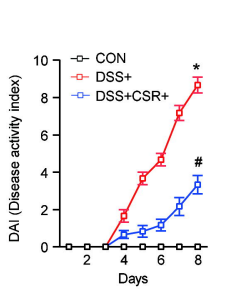

E
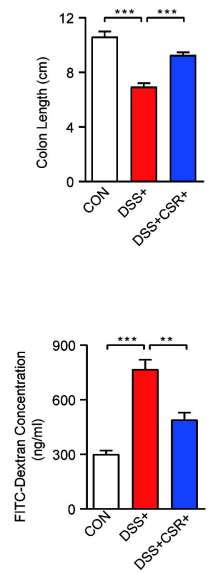

F
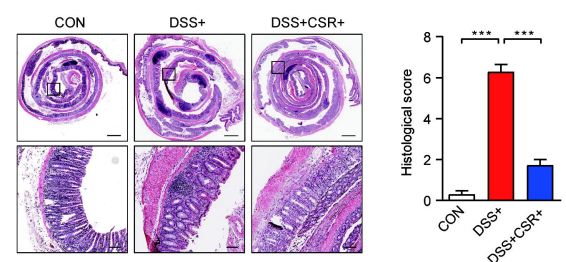

G

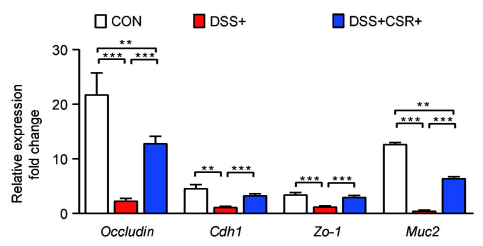

H $\quad \square$ CON $\square$ DSS+ $\square$ DSs+CSR+

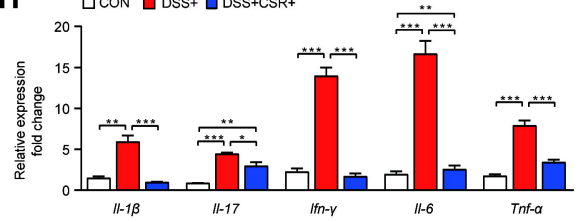

I $\quad$ CCON $\square$ DSS+ $\square D S S+C S R+$
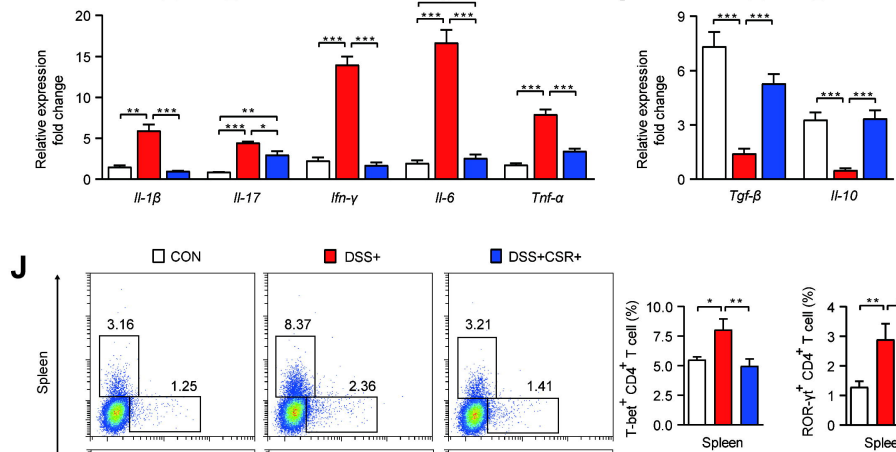

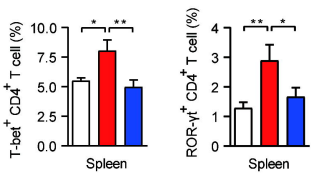
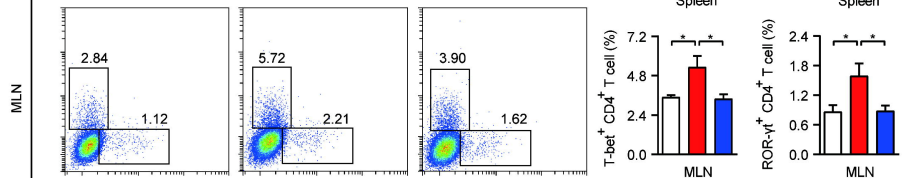

$\vec{a}$

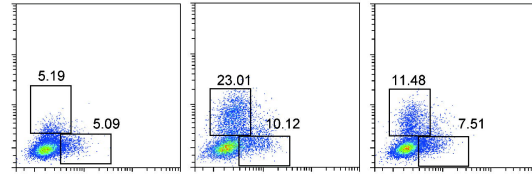

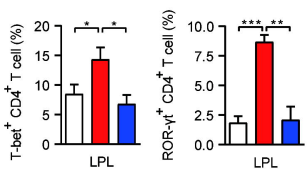
ROR-yt

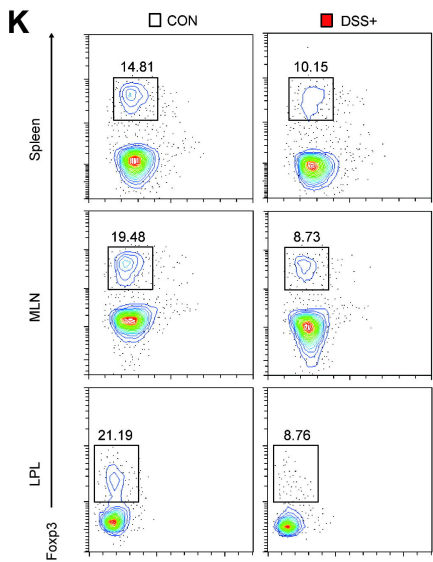

D DSS+CSR+
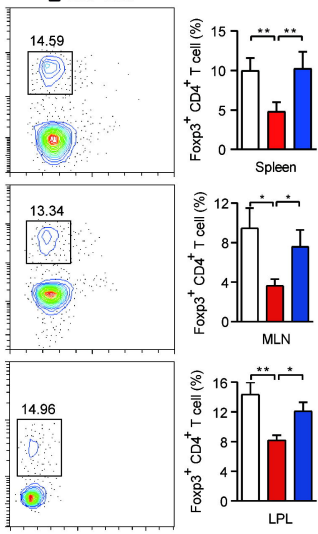
A

$\mathrm{ABX}+$

ABX+DSS+

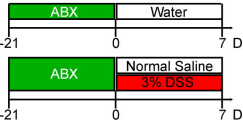

$\mathrm{ABX}+\mathrm{DSS}+\mathrm{CSR}+$

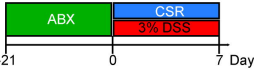

B $1150-A B X+$

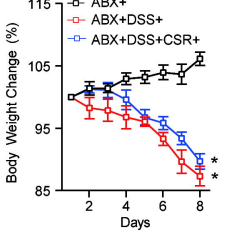

C

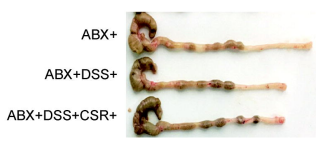

D
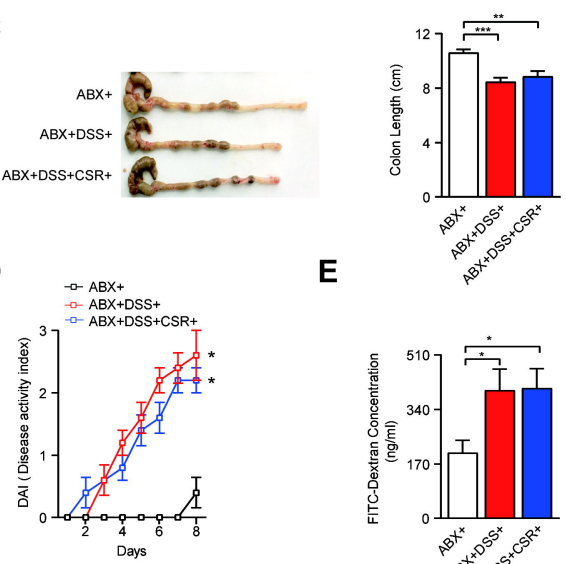

$E$

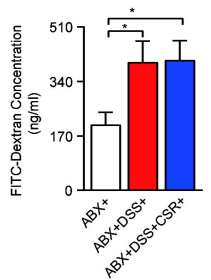

$\mathbf{F}$
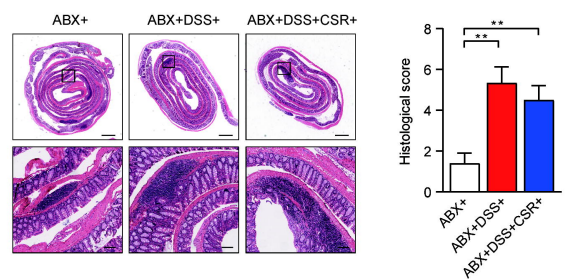

G

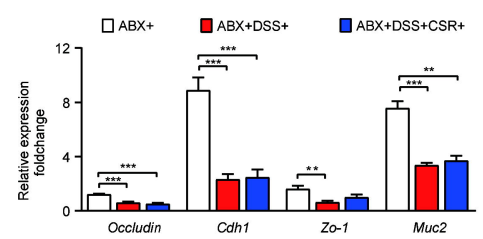

H $\square A B X+\square A B X+D S S+\square A B X+D S S+C S R+$

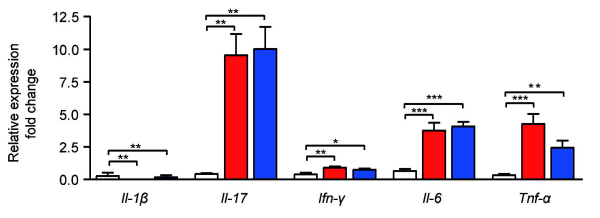

J

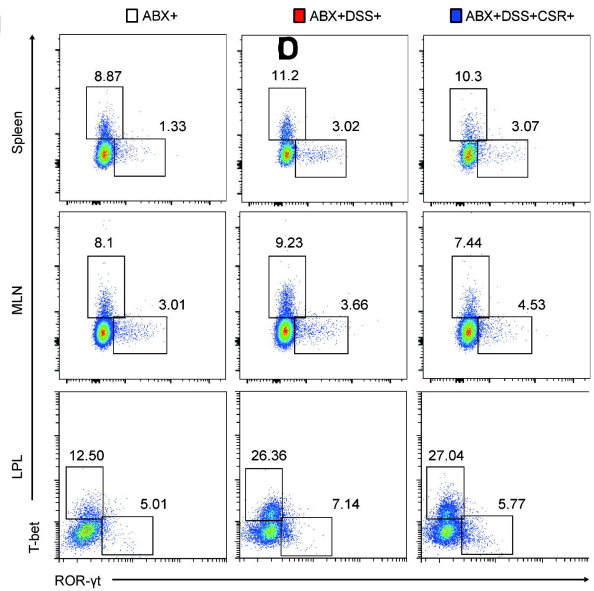

K

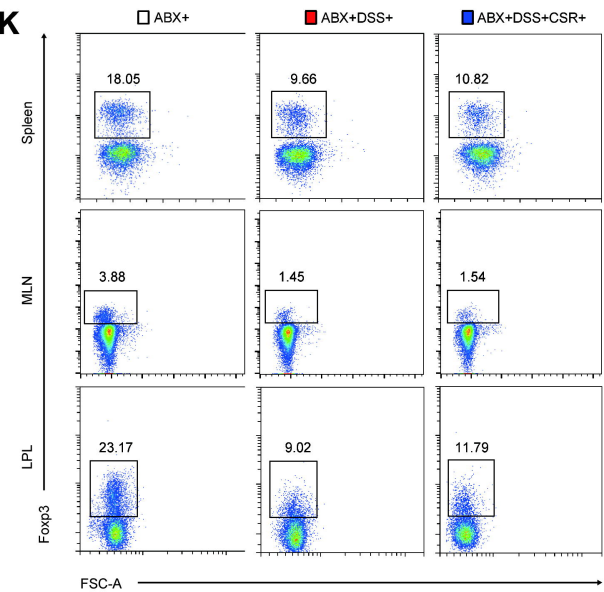

I $\square A B X+\square A B X+D S S+\square A B X+D S S+C S R+$
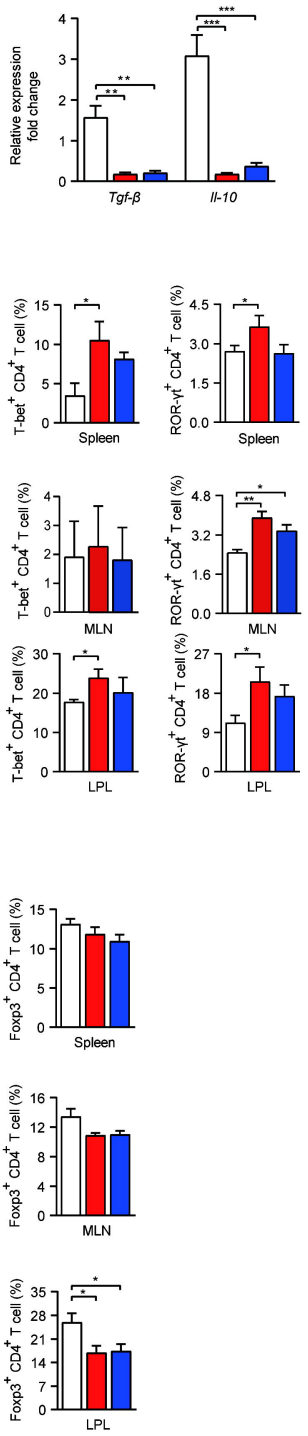
A
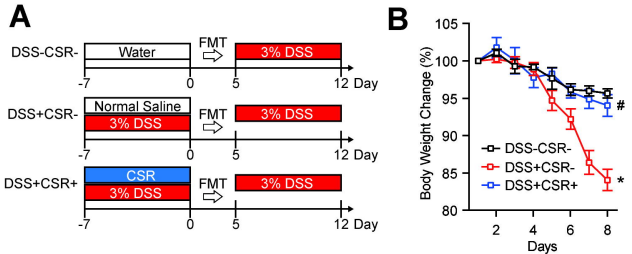

C
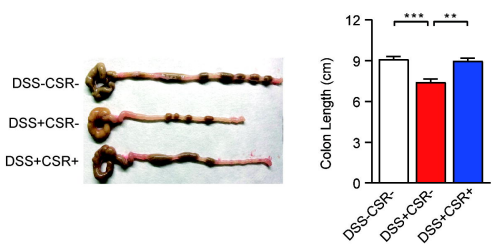

D

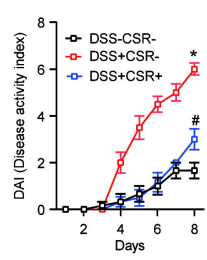

E

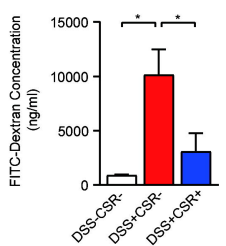

F
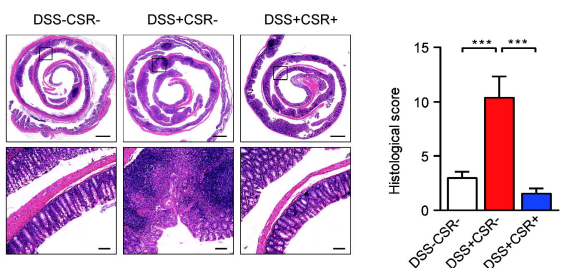

G

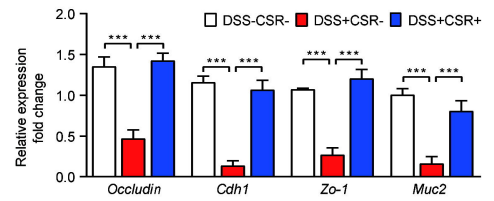

H $\square$ DSS-CSR- $\square$ DSS+CSR- $\square$ DSS+CSR+

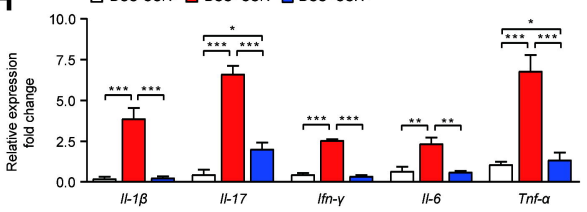

J

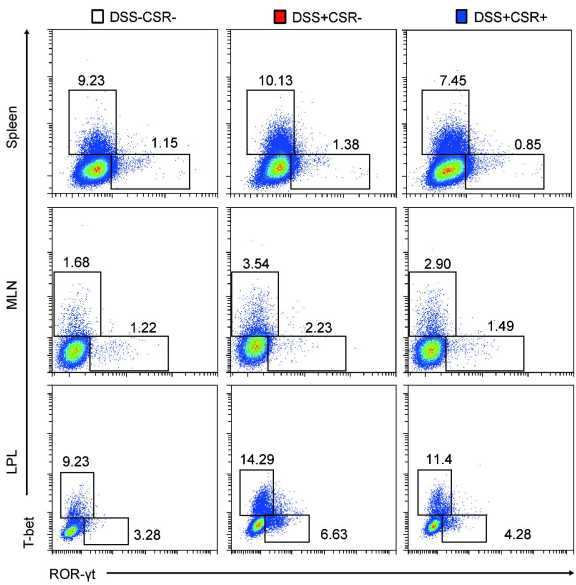

K
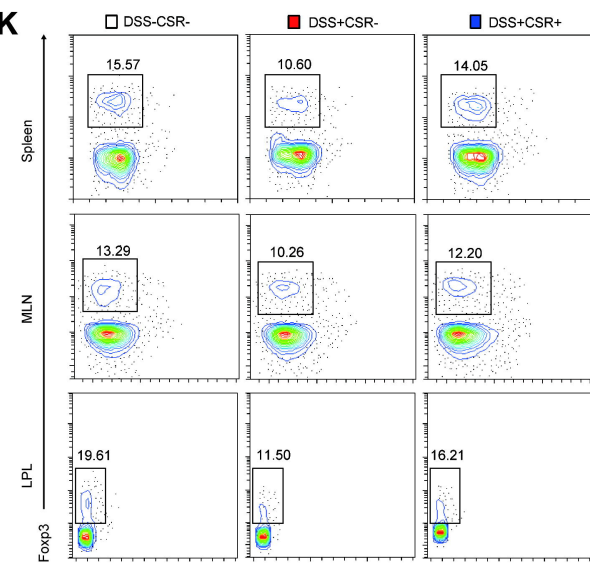

I $\square D S S-C S R-D D S S+C S R-\square D S S+C S R+$
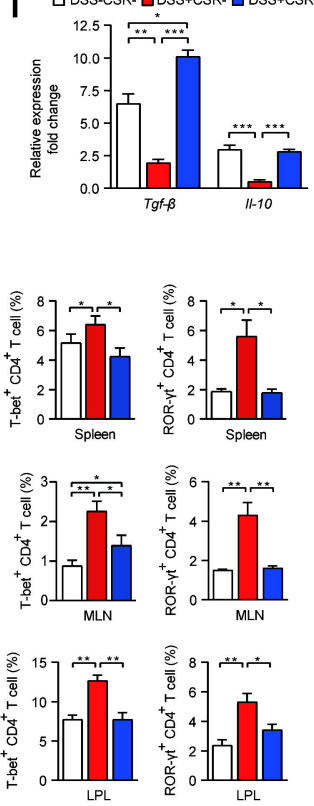
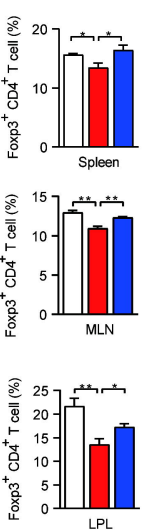
A

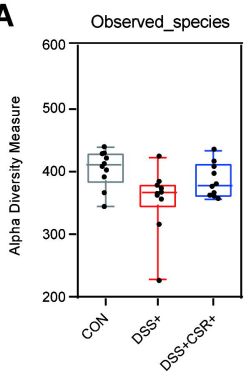

chao1

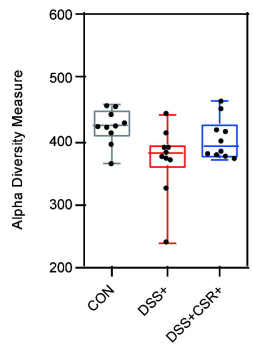

B

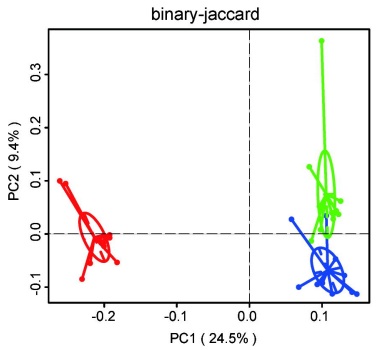

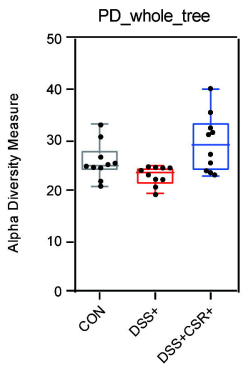

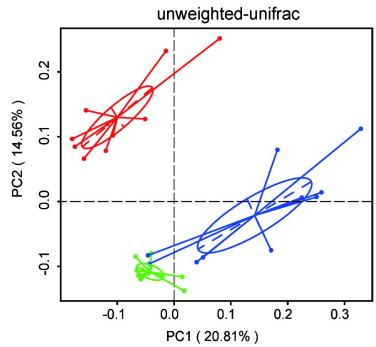

- CON - DSS+CSR+
C

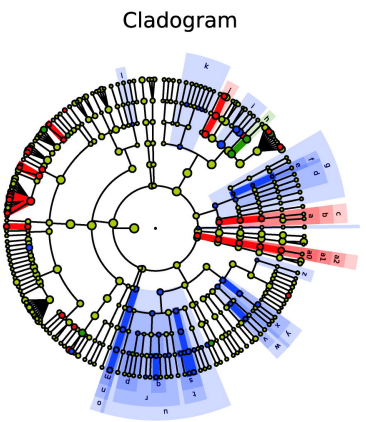

D

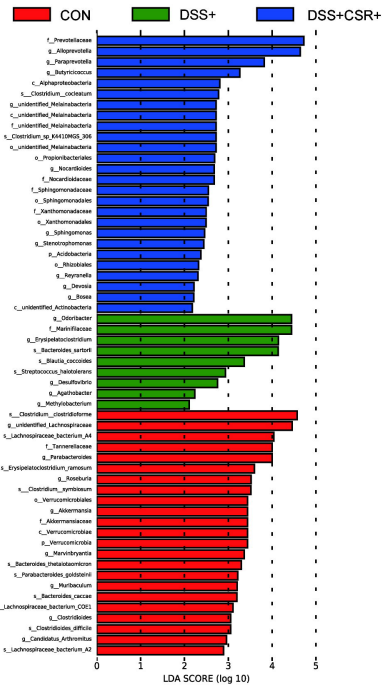

$\square$ a: f_Eggerthellaceae

$\square$ b: o_Coriobacteriales

$\square$ c: c_Coriobacteriia

d: o_Micrococcales

$\square$ e: f_Nocardioidaceae

f: o_Propionibacteriales

$\square$ g: c_unidentified_Actinobacteria

$\square$ h: f_Marinifilaceae

$\square$ i:f_Prevotellaceae

j: f_Tannerellaceae

$\square$ k: o_Chitinophagales

I: $f$ Planococcaceae

$\square \mathrm{m}: \mathrm{f} \_$_unidentified_Melainabacteria

$\square$ n: o unidentified Melainabacteria

o: c_unidentified_Melainabacteria

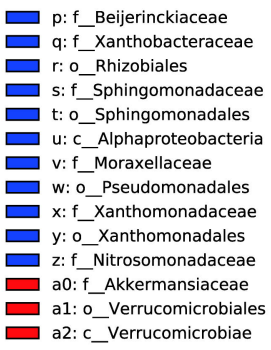

E

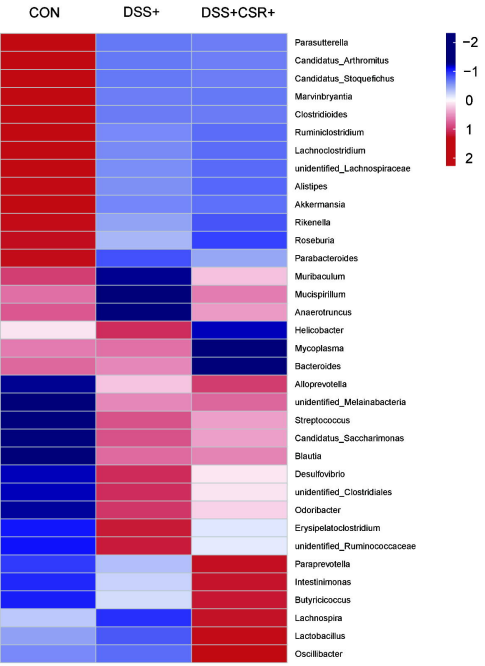


A

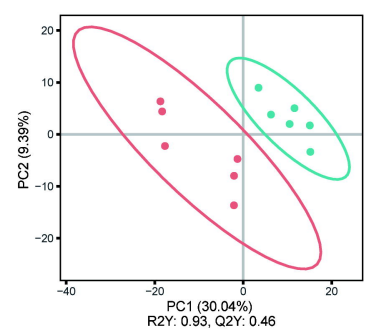

B

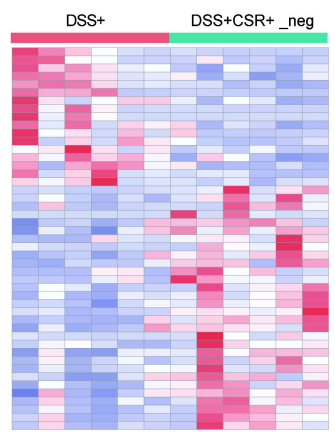

class $\Rightarrow$ DSS $+\Rightarrow$ DSS + CSR + pos

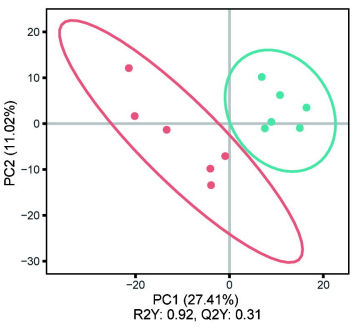

DSS+ DSS+CSR+_pos

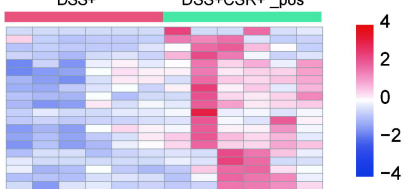

C

D

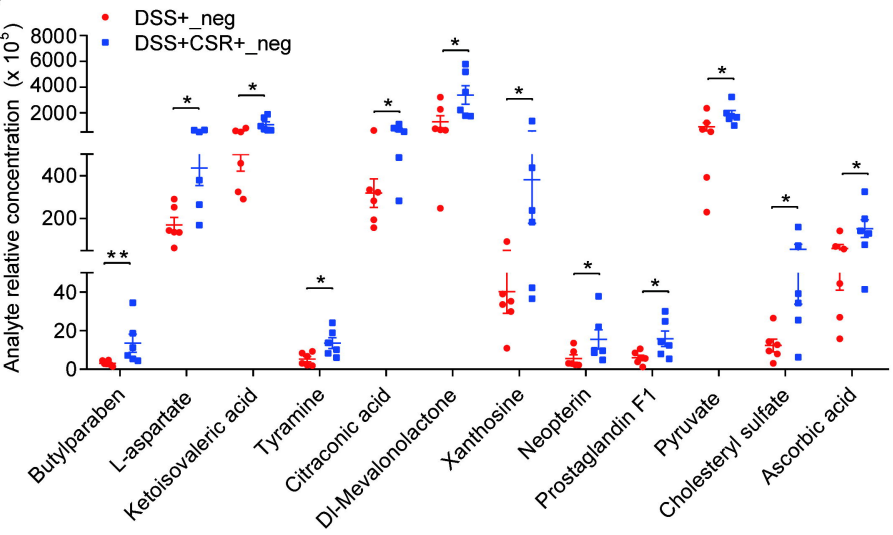

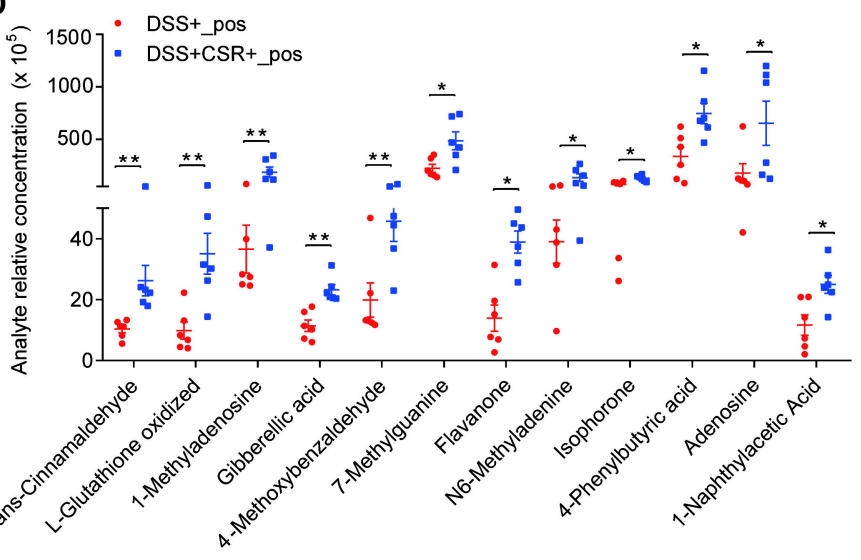


A

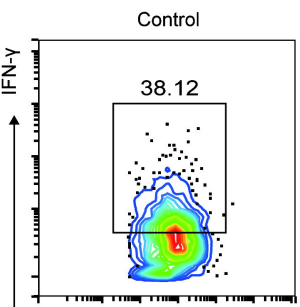

B

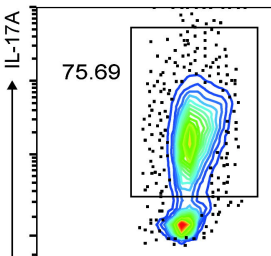

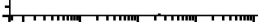

C

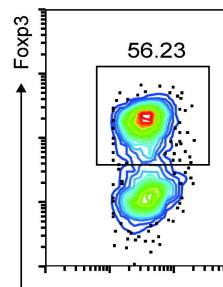

Pyruvate

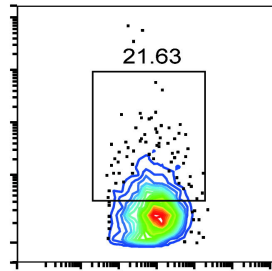

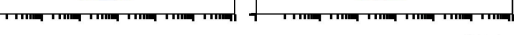
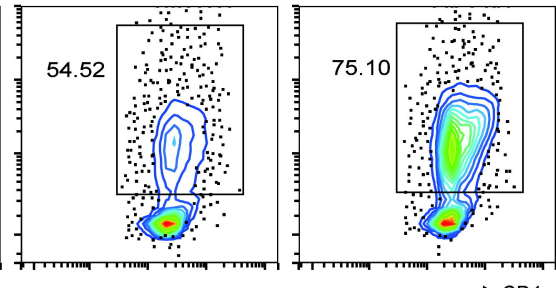

$\rightarrow$ CD4
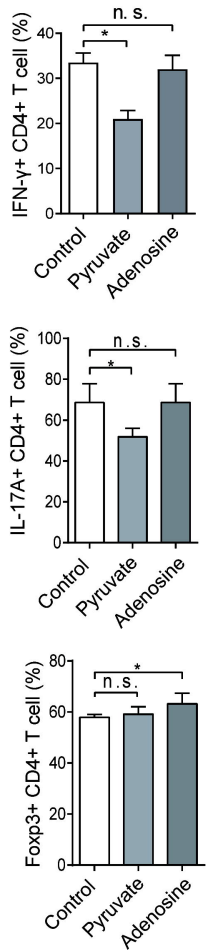


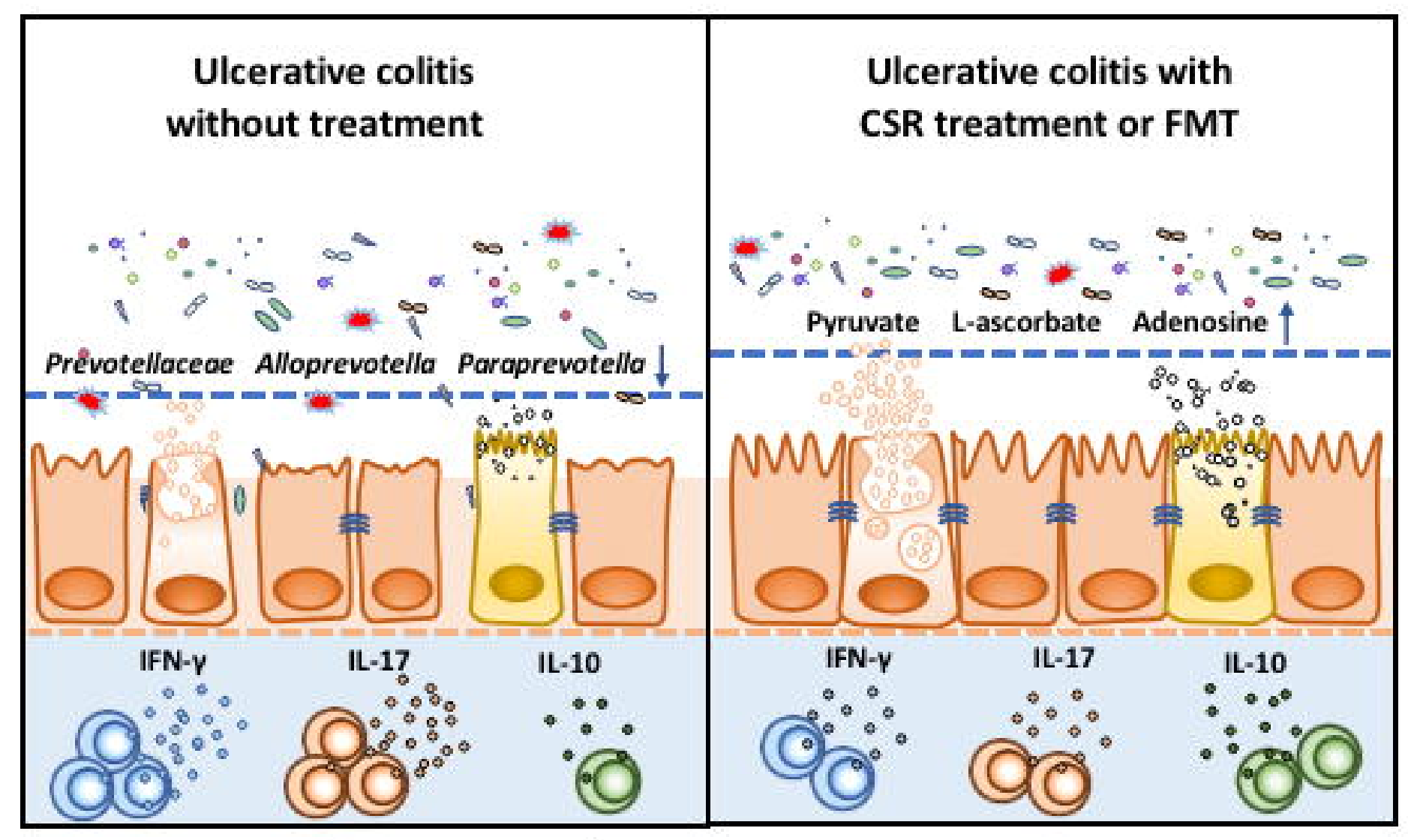

Enterocyte Goblet cell

QTh1 Th17 Treg Gut microbiota/metabolites 